The association of perseverative negative thinking with depression, anxiety and emotional distress in people with long term conditions:

\title{
A systematic review
}

Leanne Trick MSc*, Edward Watkins PhD, Stacey Windeatt MRes, Chris Dickens PhD

*Author for correspondence:

University of Exeter Medical School,

College House,

St Lukes Campus,

Heavitree Road,

Exeter EX1 2LU

L.V.Trick@exeter.ac.uk 


\section{Abstract}

Objective: Depression is common in people with long term conditions, and is associated with worse medical outcomes. Previous research shows perseverative negative thinking (e.g. worry, rumination) predicts subsequent depression and worse medical outcomes, suggesting interventions targeting perseverative negative thinking could improve depression and medical outcomes. Previous studies recruited healthy individuals, however. This review aimed to determine the temporal relationship and strength of prospective association of perseverative negative thinking with depression, anxiety and emotional distress in people with long term conditions.

Method: Four electronic databases were searched for studies including standardised measures of perseverative negative thinking and depression, anxiety or emotional distress, and which presented prospective associations. Findings were narratively synthesized.

Results: Thirty studies were identified in a range of long term conditions. Perseverative negative thinking and subsequent depression, anxiety or emotional distress were significantly correlated in the majority of studies (bivariate $r=0.23$ to $r=0.73$ ). 25 studies controlled for confounders, and in 15 perseverative negative thinking predicted subsequent depression, anxiety or emotional distress. Results varied according to condition and study quality. Six of 7 studies found bivariate associations between depression, anxiety or emotional distress and subsequent perseverative negative thinking, though 2 studies controlling for key covariates found no association. Few studies assessed the impact of perseverative negative thinking on medical outcomes.

Conclusion: Strongest evidence supported perseverative negative thinking predicting subsequent depression, anxiety and emotional distress in people with long term conditions. Further prospective research is warranted to clarify the association of perseverative negative thinking with subsequent poor medical outcomes.

\section{Keywords}

Depression, perseverative negative thinking, worry, rumination, long term conditions, systematic review

\section{Highlights}


- Perseverative negative thinking correlated with outcomes ( $r=0.23$ to $r=0.73)$.

- 25 studies controlled for confounders, and an association was found in 15 of those.

- Findings varied according to long term condition and study quality.

- Perseverative negative thinking may be a target for treatment of depression in LTCs.

\section{Introduction}

Chronic physical illnesses (i.e. long term conditions - LTCs) are conditions that cannot currently be cured but can be managed with treatment e.g. asthma, diabetes, coronary heart disease. It is estimated that 15 million people in England have a LTC, and people with LTCs account for $70 \%$ of all health and care spending[1].

Depression is common in people with chronic physical illnesses [2, 3] and is associated with worse medical outcomes such as increased morbidity and mortality[4-7], worse health-related quality of life[8-10], and increased healthcare utilisation[11, 12]. Understanding the factors contributing to the development of depression among people with LTCs could therefore: i) help identify who is at increased risk of developing depression and worse medical outcomes, ii) facilitate the stratification and personalisation of psychological and/or medical management and iii) lead to the development of novel interventions that might improve both depression and other health outcomes. Biological, psychological and social risk factors for depression have been identified among people with long term conditions [13-17], though findings from previous research are often mixed and contradictory. Furthermore, many of the risk factors identified are inter-related and the most important factors predicting (and potentially causing) depression in people with LTCs remain unclear[18].

Perseverative negative thinking is a term used to describe processes such as worry and rumination, in which individuals experience repetitive, prolonged and recurrent negative thoughts about themselves, their symptoms, their problems, or their concerns[19]. Perseverative negative thinking predicts negative affect [20-25], including the onset, maintenance and relapse of depression (e.g.[26-40]). Such thinking also predicts adverse medical outcomes, such as poor cardiovascular health, impaired wound healing and immune dysfunction[41-43]. These findings suggest that perseverative negative thinking could be a potential target for interventions aimed at improving both medical and 
psychological outcomes. Most previous prospective research into perseverative negative thinking has focussed on physically healthy populations, however. The characteristics of perseverative negative thinking and the nature of its associations with psychological outcomes among people with LTCs are not clear.

The aims of this systematic review are to clarify the temporal relationship and the strength of association between perseverative negative thinking and depression, anxiety and emotional distress among people with LTCs.

\section{Method}

This review was conducted following the guidance of the University of York Centre for Reviews and Dissemination [44] and is reported in accordance with the Preferred Reporting Items for Systematic Reviews and Meta-Analyses statement[45]. The review protocol was previously published[46].

\section{Inclusion/exclusion criteria}

Studies were included if they investigated among people with LTCs the prospective association between perseverative negative thinking, on the one hand, and depression, anxiety and emotional distress, on the other. Since we were interested in clarifying the temporal relationship, studies examining the prospective association between perseverative negative thinking and subsequent depression, anxiety or emotional distress, or the reverse association, i.e. depression, anxiety or emotional distress predicting perseverative negative thinking, were included.

Perseverative negative thinking was defined as repetitive, prolonged and recurrent negative thoughts about oneself and one's concerns (including worry, rumination, perseverative cognition, counterfactual thinking, mind wandering, post-event processing, habitual negative self-thinking and catastrophizing $[20,47,48])$. We did not include measures of constructive repetitive thought such as reflection, rehearsal, planning, and problem solving. Depression, anxiety and emotional distress was used to refer to symptoms of mood disorders and negative emotional states including negative mood. We defined LTCS broadly, as conditions which cannot be cured but which can be managed with treatment[1].

Studies meeting the following criteria were included: 
Population Studies in adults ( $>16$ years) with any LTC.

Interventions \& Comparators Use of an intervention and comparator was not a requirement.

Outcomes Studies including a standardised measure of perseverative negative thinking and a standardised measure ofdepression, anxiety or emotional distress (including negative mood and negative affect). Data were extracted on physical outcomes as well asdepression, anxiety or emotional distress, where available.

Study design Observational, prospective studies, and experimental or quasiexperimental studies. We anticipated that findings from such studies would clarify temporal relationships between perseverative negative thinking anddepression, anxiety or emotional distress, enabling tentative causal inferences to be drawn. Cross-sectional and other study designs that would not allow such inferences were excluded.

Other limiters No date or language restrictions were applied. Studies published as papers in peer reviewed journals, conference proceedings and dissertations were included.

\section{Information sources and search strategy}

MEDLINE, EMBASE, PsycINFO, and CINAHL databases were searched on 4th June 2013, and searches repeated on 19th June 2015 and $7^{\text {th }}$ Sept 2016. Search terms included subject headings and free text words relevant to: (1) depression, anxiety, emotional and psychological distress, (2) perseverative negative thinking, and (3) prospective study design (see Appendix A for search strategy). As there is no comprehensive and definitive list of LTCS available, we did not search for studies of people with LTCs using electronic search terms; suitable studies of people with LTCs were identified by hand-searching papers meeting criteria 1-3 above, to maximise sensitivity of our search strategy. Backward and forward citation searches of eligible studies were undertaken, and authors of included studies were contacted to identify any additional unpublished studies.

\section{Study selection ${ }^{1}$}

\footnotetext{
${ }^{1}$ Supplementary information regarding study selection, data extraction and quality assessment is available in Appendix B.
} 
Eligibility screening of titles and abstracts, and then of full text records, was completed independently by two reviewers. Agreement between reviewers was $80 \%$ at title/abstract screening stage, and $94 \%$ at full text screening. Disagreements were resolved by discussion, with the involvement of a third reviewer where agreement could not be reached. Findings from single, independent studies presented in multiple reports/publications were presented only once, to avoid double counting studies.

\section{Data extraction}

Data from included studies was extracted independently by two reviewers and included characteristics of the study (design, participants, measures, timing of assessments, physical health/medical outcomes included, statistical methods) and the study findings (covariates controlled, strength of association). Agreement between reviewers for the primary outcome of bivariate associations was $93 \%$, with disagreements resolved by discussion. Authors were contacted for further data in cases where suitable measures were taken but outcomes of interest were not presented in the published papers.

\section{Risk of bias}

Risk of bias within each study was independently evaluated by two reviewers using the Effective Public Health Practice Project (EPHPP) Quality Assessment Tool[49]. Ratings were made for six components (selection bias, study design, confounders, blinding, data collection methods, and withdrawals). Each component was rated strong, moderate or weak, and additionally these ratings were combined into a global quality score, such that globally strong studies had at least 4 strong and no weak ratings, moderate studies had 1 weak rating, and weak studies had more than 1 weak rating. Minor adaptions to the confounders and blinding components of the EPHPP tool were necessary due to the design of the included studies. Agreement between reviewers for global quality ratings was $73 \%$, with disagreements resolved by discussion.

\section{Data synthesis}

Characteristics and findings of included studies are summarised in tables. Findings are narratively synthesized (informed by the guidelines of the ESRC methods 
programme[50] where possible) based on grouping studies according to: i) type of perseverative negative thinking measured, ii) type of psychological outcome measured (i.e. depression, anxiety or emotional distress), iii) timing of follow-up (6 months or less versus more than 6 months), iv) type of LTC, and v) type of analysis conducted (bivariate versus multivariable).

\section{Results}

\section{Study selection}

Details of study selection are shown in Figure 1. Thirty eligible studies were included in the review [51-82]. Authors of a further 46 potentially eligible studies were contacted for additional data; authors of 15 studies were unable to provide additional data, and authors of 31 did not respond. It was not possible to contact authors of a further 2 studies for additional information and these studies were therefore excluded. 
Figure 1: PRISMA flowchart

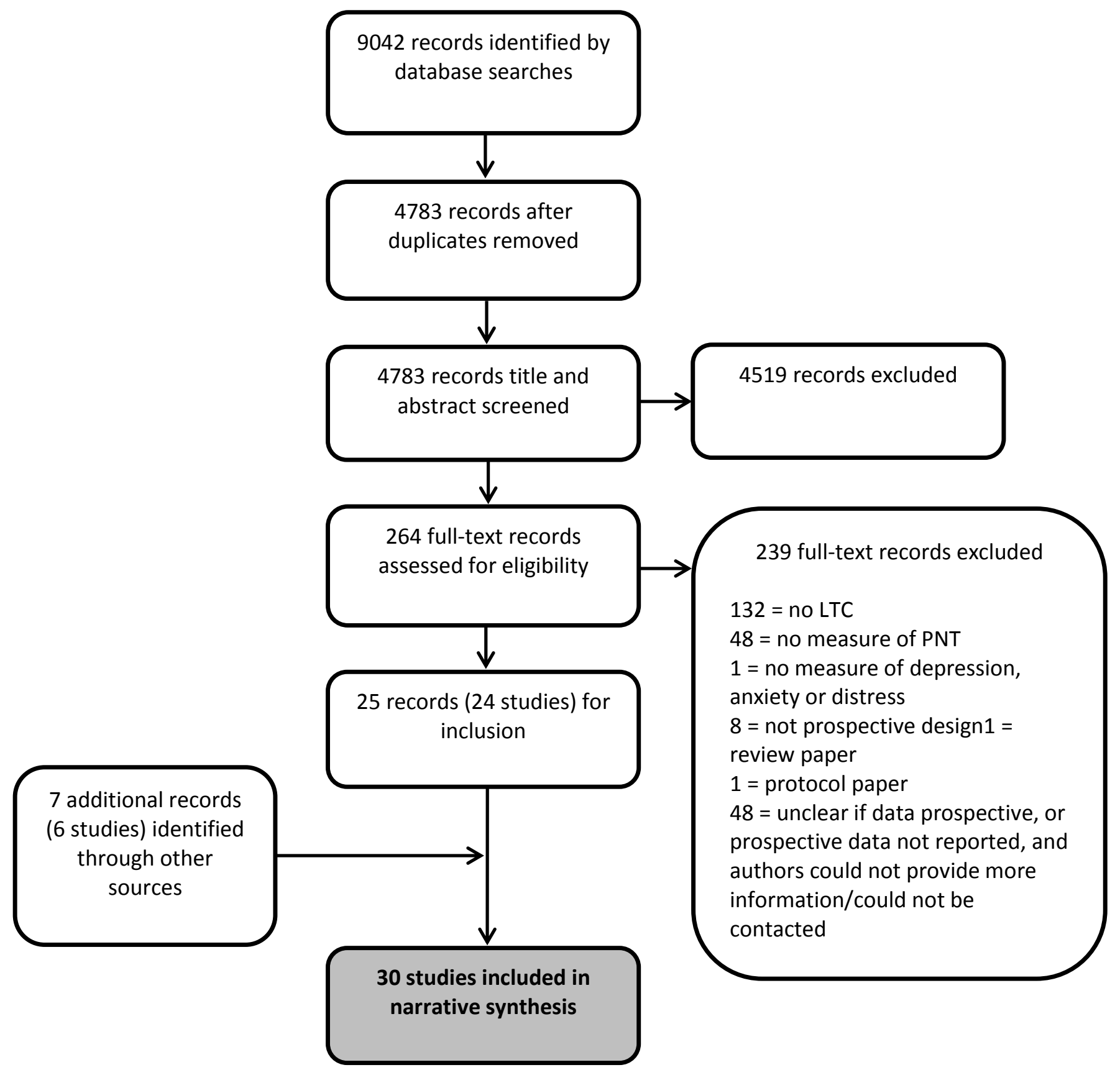




\section{Study characteristics}

There were 26 observational cohort studies, 3 prospective evaluations of an intervention, and 1 randomised controlled trial. Characteristics of all included studies are given in Table 1.

Samples Sample sizes ranged between $n=22$ to $n=560$ in relevant prospective analyses (median $n=99$ ). Mean age ranged between 24.3 to 70.1 years, with subjects ranging from $0 \%$ to $100 \%$ female.

There were 5 studies in people with vascular disease $[52,54,55,57,73,76]), 4$ in rheumatoid arthritis[63, 69-71], 10 in cancer[51, 53, 56, 58, 66, 67, 74, 75, 78, 81], 2 in individuals experiencing infertility[64, 65], 2 in muscular dystrophy or cerebral palsy[61, 68], and 7 in chronic pain-related conditions $[60,62,72,77,79,80,82]$.

Measures Included studies measured five types of perseverative negative thinking (rumination, catastrophizing, worry, anxious pre-occupation and preoccupation with death) using a total of 15 different measures. Six types of psychological outcome were identified (depression, anxiety, psychological distress, psychological functioning, negative affect and negative mood) measured using 15 different scales.

Timing of assessments Duration of LTC at baseline assessment was up to 1 month in 6 studies, up to 1 year in 3 studies, more than one year in 12 studies (maximum 16.5 years), and unclear in 9 studies. Median duration of LTC was 12.6 months. In 16 studies there was one follow-up assessment, in 12 studies there were between 2 and 5 follow-ups, and in 2 studies follow-ups took the form of daily diary measures completed over $14-30$ days. The median number of follow-up assessments was 1 . Follow-up assessments took place within 1 month ( 8 studies), between 1 and 6 months (17 studies), 6 months to 1 year ( 11 studies), and 1 to 2 years ( 5 studies). The median time to follow-up was 6 months. 
Table 1: Characteristics of included studies

\begin{tabular}{|c|c|c|c|c|c|c|c|c|c|c|}
\hline \multirow[t]{2}{*}{ ID } & \multirow[t]{2}{*}{ Authors and date } & \multirow[t]{2}{*}{ Condition } & \multicolumn{2}{|c|}{ Sample size } & \multirow{2}{*}{$\begin{array}{l}\text { Mean } \\
\text { age } \\
\text { (years) }^{b}\end{array}$} & \multirow{2}{*}{$\begin{array}{l}\text { Males } \\
(\%)^{b}\end{array}$} & \multirow[t]{2}{*}{ Sample } & \multirow[t]{2}{*}{ Assessments } & \multirow[t]{2}{*}{ PNT measure } & \multirow{2}{*}{$\begin{array}{l}\text { Anxiety, depression or mood } \\
\text { measure }\end{array}$} \\
\hline & & & Recruited & Analysed $^{a}$ & & & & & & \\
\hline 1 & Denton et al. $(2012,2011)$ & $\begin{array}{l}\text { Acute } \\
\text { coronary } \\
\text { syndrome }\end{array}$ & 457 & 387 & 61.1 & 58.6 & $\begin{array}{l}\text { Eligible patients on coronary care } \\
\text { and cardiac step-down units of } \\
\text { three hospitals; USA }\end{array}$ & $\begin{array}{l}\text { T1=within } 1 \text { week of } \\
\text { index event, } T 2=3 \\
\text { months post-ACS }\end{array}$ & $\begin{array}{l}\text { Ruminative responses scale } \\
\text { of the Response Styles } \\
\text { Questionnaire @ T1 and T2 }\end{array}$ & $\begin{array}{l}\text { Beck Depression Inventory } \\
@ \mathrm{~T} 1 \text { and } \mathrm{T} 2\end{array}$ \\
\hline 2 & Garnefski \& Kraaij (2010) & $\begin{array}{l}\text { Myocardial } \\
\text { infarction }\end{array}$ & 160 & 88 & 56.0 & 80.7 & $\begin{array}{l}\text { Patients aged }<70 \text { years from } \\
\text { cardiology outpatient clinic } \\
\text { database who had received PCl in } \\
\text { the previous 3-12 months; } \\
\text { Netherlands }\end{array}$ & $\begin{array}{l}\text { T1=within 3-12 } \\
\text { months following PCl, } \\
\text { T2=12 months later }\end{array}$ & $\begin{array}{l}\text { Rumination and } \\
\text { catastrophizing subscales of } \\
\text { the Cognitive Emotion } \\
\text { Regulation Questionnaire @ } \\
\text { T1 }\end{array}$ & $\begin{array}{l}\text { Hospital Anxiety \& } \\
\text { Depression Scale @ T1 and } \\
\text { T2 (depression subscale) }\end{array}$ \\
\hline 3 & Vogele et al. (2012) & $\begin{array}{l}\text { Myocardial } \\
\text { infarction }\end{array}$ & 36 & $24^{c}$ & 57.6 & 89 & $\begin{array}{l}\text { Patients with acute first MI } \\
\text { contacted in hospital; Germany }\end{array}$ & $\begin{array}{l}\mathrm{T} 1=5-15 \text { days post }-\mathrm{MI}, \\
\mathrm{T} 2=6-8 \text { weeks post-MI, } \\
\mathrm{T} 3=6 \text { months post }-\mathrm{MI}\end{array}$ & $\begin{array}{l}\text { Rumination subscale of the } \\
\text { Trierer Skalen zur } \\
\text { Krankheitbewaltigung } \\
\text { (Coping questionnaire) @ T1 }\end{array}$ & $\begin{array}{l}\text { Centre for Epidemiologic } \\
\text { Studies Depression Scale @ } \\
\mathrm{T} 1, \mathrm{~T} 2 \text {, and } \mathrm{T} 3\end{array}$ \\
\hline 4 & Baker (2014) & $\begin{array}{l}\text { Coronary } \\
\text { heart disease }\end{array}$ & 101 & 85 & $\begin{array}{l}66-75 \\
\text { modal } \\
\text { range }\end{array}$ & 76.2 & $\begin{array}{l}\text { Inpatients or outpatients } \\
\text { presenting for cardiac care at } \\
\text { hospital; UK }\end{array}$ & $\begin{array}{l}\text { T1=after attendance } \\
\text { at inpatient or } \\
\text { outpatient cardiology } \\
\text { service, } \mathrm{T} 2=3 \text { months } \\
\text { later }\end{array}$ & $\begin{array}{l}\text { Ruminative Responses Scale } \\
\text { of the Response Styles } \\
\text { Questionnaire @ } 1 \text { and T2 }\end{array}$ & $\begin{array}{l}\text { Patient Health } \\
\text { Questionnaire-9 (depression) } \\
\text { @ T1 and T2 }\end{array}$ \\
\hline 5 & Xiao et al. (2011) & Hypertension & 650 & 560 & 55.4 & 51.8 & $\begin{array}{l}\text { Randomly selected from } 1200 \\
\text { hypertension patients at one } \\
\text { hospital; China }\end{array}$ & $\begin{array}{l}\text { T1=following at least } 1 \\
\text { year of hypertension, } \\
T 2=6 \text { months later }\end{array}$ & $\begin{array}{l}\text { Rumination and } \\
\text { catastrophizing subscales of } \\
\text { the Cognitive Emotion } \\
\text { Regulation Questionnaire @ } \\
\text { T1 }\end{array}$ & $\begin{array}{l}\text { Centre for Epidemiologic } \\
\text { Studies Depression Scale @ } \\
\text { T1 and T2 }\end{array}$ \\
\hline 6 & Keefe et al. (1989) & $\begin{array}{l}\text { Rheumatoid } \\
\text { arthritis }\end{array}$ & Unclear & 223 & 52.7 & 25 & $\begin{array}{l}\text { Patients identified by rheumatology } \\
\text { practices; USA }\end{array}$ & $\begin{array}{l}T 1=\text { within } 7 \text { years of } \\
\text { diagnosis, } \mathrm{T} 2=6 \\
\text { months later }\end{array}$ & $\begin{array}{l}\text { Catastrophizing subscale of } \\
\text { the Coping Strategies } \\
\text { Questionnaire @ T1 and T2 }\end{array}$ & $\begin{array}{l}\text { Centre for Epidemiologic } \\
\text { Studies Depression Scale @ } \\
\text { T1 and T2 }\end{array}$ \\
\hline 7 & Sturgeon \& Zautra (2013) & $\begin{array}{l}\text { Rheumatoid } \\
\text { arthritis }\end{array}$ & 231 & $\begin{array}{l}93 \% \text { diary } \\
\text { completion }\end{array}$ & 55.0 & 30.4 & $\begin{array}{l}\text { Patients invited to participate at } \\
\text { health fairs, Arthritis Foundation } \\
\text { members, local physicians offices, } \\
\text { Veterans Administration Hospital; } \\
\text { USA }\end{array}$ & $\begin{array}{l}\text { Daily diary for } 30 \text { days } \\
\text { (once per day), } \\
\text { starting an average of } \\
13.6 \text { years post- } \\
\text { diagnosis }\end{array}$ & $\begin{array}{l}2 \text { items from the } \\
\text { catastrophizing subscale of } \\
\text { the Coping Strategies } \\
\text { Questionnaire @ daily }\end{array}$ & $\begin{array}{l}\text { Positive and Negative Affect } \\
\text { Schedule; depressive } \\
\text { symptoms @ daily }\end{array}$ \\
\hline 8 & Schiaffano \& Revenson (1995) & $\begin{array}{l}\text { Rheumatoid } \\
\text { arthritis }\end{array}$ & 101 & 64 & NR & 20 & $\begin{array}{l}\text { Eligible patients from hospital } \\
\text { outpatient clinic, or from } \\
\text { rheumatology practices; USA }\end{array}$ & $\begin{array}{l}\mathrm{T} 1=\text { within } 2 \text { years of } \\
\text { diagnosis, } \mathrm{T} 2=18 \\
\text { months later }\end{array}$ & $\begin{array}{l}\text { 5-point Likert scale of } \\
\text { rumination @ T2 }\end{array}$ & $\begin{array}{l}\text { Centre for Epidemiologic } \\
\text { Studies Depression Scale @ } \\
\text { T1 and T2 }\end{array}$ \\
\hline 9 & Sharpe et al. (2001) & Rheumatoid & 53 & 22 & 55.1 & 30 & Consecutive patients at & T1=within 2 years of & Catastrophizing subscale of & Hospital Anxiety \& \\
\hline
\end{tabular}




\begin{tabular}{|c|c|c|c|c|c|c|c|c|c|c|}
\hline & & arthritis & & & & & rheumatology clinics of three & diagnosis,T2=3 & the Coping Strategies & Depression Scale @ T1, T2, \\
\hline 10 & Wang et al. (2014) & Breast cancer & 509 & 504 & 48.3 & 0 & $\begin{array}{l}\text { Eligible women who had } \\
\text { undergone surgery for breast } \\
\text { cancer at two hospitals; China }\end{array}$ & $\begin{array}{l}\text { T1=approx. } 1 \text { week } \\
\text { post-diagnosis (5-7 } \\
\text { days post-surgery), } \\
\text { T2=1 month later }\end{array}$ & $\begin{array}{l}\text { Rumination and } \\
\text { catastrophizing subscales of } \\
\text { the Cognitive Emotion } \\
\text { Regulation Questionnaire @ } \\
\text { T1 }\end{array}$ & $\begin{array}{l}\text { Centre for Epidemiologic } \\
\text { Studies Depression Scale @ } \\
\text { T1 and T2 }\end{array}$ \\
\hline 11 & Andreu et al. (2012) & Breast cancer & $174^{\mathrm{d}}$ & 102 & 50.5 & 0 & $\begin{array}{l}\text { Consecutive patients attending pre- } \\
\text { operative visit at department of } \\
\text { surgery at oncology clinic; Spain }\end{array}$ & $\begin{array}{l}\text { T1=pre-surgery (at } \\
\text { preliminary diagnosis), } \\
\text { T2=2-7 days post- } \\
\text { surgery, } \mathrm{T} 3=\text { at } \\
\text { definitive diagnosis, } \\
\text { T4=at chemotherapy }\end{array}$ & $\begin{array}{l}\text { Anxious preoccupation } \\
\text { subscale of the Mental } \\
\text { Adjustment to Cancer Scale } \\
\text { @ T4 }\end{array}$ & $\begin{array}{l}\text { Brief Symptom Inventory } 18 \\
\text { (distress) @ T1, T2, T3 and } \\
\text { T4 }\end{array}$ \\
\hline 12 & Ferrero et al. (1994) & Breast cancer & 68 & 66 & 53.0 & 0 & $\begin{array}{l}\text { Consecutive newly diagnosed } \\
\text { patients attending hospital } \\
\text { oncology clinic; Spain }\end{array}$ & $\begin{array}{l}\text { T1=after diagnosis } \\
\text { (approx. } 1 \text { month } \\
\text { post-surgery), } \mathrm{T} 2=4 \\
\text { months post-surgery, } \\
\text { T3=7 months post- } \\
\text { surgery }\end{array}$ & $\begin{array}{l}\text { Anxious preoccupation } \\
\text { subscale of the Mental } \\
\text { Adjustment to Cancer Scale } \\
@ \mathrm{~T} 1, \mathrm{~T} 2 \text { and } \mathrm{T} 3\end{array}$ & $\begin{array}{l}\text { Breast Cancer Quality of Life } \\
\text { Questionnaire (psychological } \\
\text { distress subscale) @ T1, T2 } \\
\text { and T3 }\end{array}$ \\
\hline 13 & Groarke et al. (2013) & Breast cancer & 355 & 221 & 24.3 & 0 & $\begin{array}{l}\text { Consecutive eligible patients } \\
\text { attending a breast symptomatic } \\
\text { unit at a University-affiliated } \\
\text { hospital; Ireland }\end{array}$ & $\begin{array}{l}\text { T1=within } 1 \text { week of } \\
\text { diagnosis, } \mathrm{T} 2=4 \\
\text { months later }\end{array}$ & $\begin{array}{l}\text { Anxious preoccupation } \\
\text { subscale of the Mental } \\
\text { Adjustment to Cancer Scale } \\
\text { @ T1 and T2 }\end{array}$ & $\begin{array}{l}\text { Hospital Anxiety \& } \\
\text { Depression Scale; Positive } \\
\text { and Negative Affect } \\
\text { Schedule @ T1 and T2 }\end{array}$ \\
\hline 14 & Lam et al. (2013) & $\begin{array}{l}\text { Advanced } \\
\text { breast cancer }\end{array}$ & 228 & 192 & 53.5 & 0 & $\begin{array}{l}\text { Hospital outpatients identified } \\
\text { from clinic lists of } 6 \\
\text { breast/oncology clinics; China }\end{array}$ & $\begin{array}{l}\mathrm{T} 1=\text { post- diagnosis } \\
\text { (awaiting or receiving } \\
\text { initial chemotherapy), } \\
\mathrm{T} 2=6 \text { weeks, } \mathrm{T} 3=3 \\
\text { months, } \mathrm{T} 4=6 \text { months, } \\
\mathrm{T} 5=12 \text { months later }\end{array}$ & $\begin{array}{l}\text { Cancer-related Rumination } \\
\text { Scale @T1 }\end{array}$ & $\begin{array}{l}\text { Hospital Anxiety \& } \\
\text { Depression Scale @ T1, T2 } \\
\text { and T5 }\end{array}$ \\
\hline 15 & Thomsen et al. (2013) & Colon cancer & 67 & 54 & 63.5 & 54 & $\begin{array}{l}\text { Patients referred for chemotherapy } \\
\text { at hospital oncology department; } \\
\text { Denmark }\end{array}$ & $\begin{array}{l}\text { T1=1-7 months post- } \\
\text { diagnosis (mean } 72 \\
\text { days), } T 2=8 \text { months } \\
\text { later }\end{array}$ & $\begin{array}{l}\text { Rumination-Reflection } \\
\text { Questionnaire @ T1 and T2 }\end{array}$ & $\begin{array}{l}\text { Beck Depression Inventory } \\
@ \mathrm{~T} 1 \text { and T2 }\end{array}$ \\
\hline 16 & Couper et al. (2010) & $\begin{array}{l}\text { Early and } \\
\text { advanced } \\
\text { prostate }\end{array}$ & $\begin{array}{l}367 \text { ( } 211 \\
\text { early; } 156 \\
\text { advanced) }\end{array}$ & $\begin{array}{l}265(178 \\
\text { early; } 87 \\
\text { advanced) }\end{array}$ & $\begin{array}{l}66.2 \\
\text { early; } \\
70.1\end{array}$ & 100 & $\begin{array}{l}\text { Consecutive patients recruited by } \\
\text { their oncologist/urologist from } \\
\text { public hospitals and practices; }\end{array}$ & $\begin{array}{l}\text { T1=after diagnosis, at } \\
\text { beginning treatment } \\
\text { (early) or after }\end{array}$ & $\begin{array}{l}\text { Anxious preoccupation } \\
\text { subscale of the Mental } \\
\text { Adjustment to Cancer Scale }\end{array}$ & $\begin{array}{l}\text { Brief Symptom Inventory } 53 \\
\text { (anxiety and depression) @ } \\
\text { T1 and T2 }\end{array}$ \\
\hline
\end{tabular}




\begin{tabular}{|c|c|c|c|c|c|c|c|c|c|c|}
\hline & & cancer & & & advanced & & Australia & patients informed & @ T1 and T2 & \\
\hline 17 & Lehto \& Cimprich (2009) & $\begin{array}{l}\text { Suspected } \\
\text { lung cancer }\end{array}$ & 52 & 42 & 64.0 & 64.3 & $\begin{array}{l}\text { Patients undergoing surgical } \\
\text { evaluation for lung cancer at a } \\
\text { comprehensive cancer center; USA }\end{array}$ & $\begin{array}{l}\mathrm{T} 1=\text { at diagnosis ( } 14 \\
\text { days prior to surgery), } \\
\mathrm{T} 2=5-6 \text { weeks later }\end{array}$ & $\begin{array}{l}\text { Penn State Worry } \\
\text { Questionnaire @ T1 and T2 }\end{array}$ & $\begin{array}{l}\text { State-Trait Anxiety Inventory } \\
\text { @ T1 and T2 }\end{array}$ \\
\hline 18 & Lampic et al. (1994) & Mixed cancer & 197 & 121 & 61.0 & 37 & $\begin{array}{l}\text { Consecutive patients scheduled for } \\
\text { hospital appointment at oncology } \\
\text { clinic; Sweden }\end{array}$ & $\begin{array}{l}\text { T1=at clinic } \\
\text { appointment (median } \\
6 \text { yrs from diagnosis), } \\
\text { T2=few days after } \\
\text { appointment, } T 3=3 \\
\text { weeks after } \\
\text { appointment }\end{array}$ & $\begin{array}{l}\text { Anxious preoccupation } \\
\text { subscale of the Mental } \\
\text { Adjustment to Cancer Scale } \\
@ \mathrm{~T} 2 \text {; Cancer-related worry } \\
@ \mathrm{~T} 1, \mathrm{~T} 2 \text {, and T3 }\end{array}$ & $\begin{array}{l}\text { Visual analogue ratings of } \\
\text { anxiety @ T1, T2 and T3 }\end{array}$ \\
\hline 19 & Vollmer et al. (2011) & $\begin{array}{l}\text { Haematologic } \\
\text { malignancy }\end{array}$ & $102^{e}$ & 45 & 46.7 & 51.6 & $\begin{array}{l}\text { Consecutively enrolled patients } \\
\text { with haematologic malignancies } \\
\text { identified from weekly lists of } \\
\text { inpatients; Germany }\end{array}$ & $\begin{array}{l}\text { T1=within } 7 \text { days post- } \\
\text { admission, } T 2=\text { at least } \\
4 \text { weeks later }\end{array}$ & $\begin{array}{l}\text { Preoccupation with death } \\
\text { subscale of the Subjective } \\
\text { Assessment of the Course of } \\
\text { Disease \& Death @ T1 and } \\
\text { T2 }\end{array}$ & $\begin{array}{l}\text { Hospital Anxiety \& } \\
\text { Depression Scale @ T1 and } \\
\text { T2 }\end{array}$ \\
\hline 20 & Kraaij et al. (2008) & $\begin{array}{l}\text { Definitive } \\
\text { infertility }\end{array}$ & 169 & 99 & 41.0 & 38 & $\begin{array}{l}\text { Individuals with definitive infertility } \\
\text { responding to announcements in } \\
\text { local media and online self-help } \\
\text { groups; Netherlands }\end{array}$ & $\begin{array}{l}\mathrm{T} 1=\text { average } 5 \text { years } \\
\text { post-diagnosis, } \mathrm{T} 2=2 \\
\text { years later }\end{array}$ & $\begin{array}{l}\text { Rumination and } \\
\text { catastrophizing subscales of } \\
\text { the Cognitive Emotion } \\
\text { Regulation Questionnaire @ } \\
\text { T1 and T2 }\end{array}$ & $\begin{array}{l}\text { Depression subscale of the } \\
\text { Symptom Check List @ T1 } \\
\text { and T2 }\end{array}$ \\
\hline 21 & Kraaij et al. (2010) & Infertility & 313 & 139 & 35.0 & 22 & $\begin{array}{l}\text { Patients who had attended an } \\
\text { infertility clinic for treatment within } \\
\text { the previous } 4 \text { months; } \\
\text { Netherlands }\end{array}$ & $\begin{array}{l}T 1=\text { within } 4 \text { months of } \\
\text { most recent } \\
\text { treatment, } T 2=9 \\
\text { months later }\end{array}$ & $\begin{array}{l}\text { Rumination and } \\
\text { catastrophizing subscales of } \\
\text { the Cognitive Emotion } \\
\text { Regulation Questionnaire @ } \\
\text { T1 }\end{array}$ & $\begin{array}{l}\text { Hospital Anxiety \& } \\
\text { Depression Scale @ T1 and } \\
\text { T2 }\end{array}$ \\
\hline 22 & Nieto et al. (2012) & $\begin{array}{l}\text { Muscular } \\
\text { dystrophy }\end{array}$ & $395^{f}$ & 107 & 50.2 & 43 & $\begin{array}{l}\text { Participants identified from } \\
\text { National Registry of Myotonic } \\
\text { Dystrophy \& Facioscapulohumeral } \\
\text { Muscular Dystrophy Patients \& } \\
\text { Family Members, and from } \\
\text { neuromuscular disease clinic; USA }\end{array}$ & $\begin{array}{l}\mathrm{T} 1=\text { average } 16.5 \text { years } \\
\text { post-diagnosis, } \mathrm{T} 2=24 \\
\text { months later }\end{array}$ & $\begin{array}{l}\text { Catastrophizing subscale of } \\
\text { the Coping Strategies } \\
\text { Questionnaire @ T1; Pain } \\
\text { Catastrophizing Scale @ T2 }\end{array}$ & $\begin{array}{l}5 \text { item SF-36 mental health } \\
\text { scale (psychological } \\
\text { functioning) @ T1 and T2 }\end{array}$ \\
\hline 23 & Jensen et al. (2006) & $\begin{array}{l}\text { Cerebral } \\
\text { palsy }\end{array}$ & 48 & 48 & 40.1 & 50 & $\begin{array}{l}\text { Patients who participated in a } \\
\text { previous cross-sectional study; USA }\end{array}$ & $\begin{array}{l}\mathrm{T} 1=\text { after previous } \\
\text { study (pain duration } \\
\geq 3 \text { months) }, \mathrm{T} 2=6 \\
\text { months later }\end{array}$ & $\begin{array}{l}\text { Catastrophizing subscale of } \\
\text { the Coping Strategies } \\
\text { Questionnaire @ T1 and T2 }\end{array}$ & $\begin{array}{l}\text { Centre for Epidemiologic } \\
\text { Studies Depression Scale @ } \\
\text { T1 and T2 }\end{array}$ \\
\hline
\end{tabular}




\begin{tabular}{|c|c|c|c|c|c|c|c|c|c|c|}
\hline 24 & Turner et al. (2004) & $\begin{array}{l}\text { Tempromand } \\
\text { ibular } \\
\text { disorder }\end{array}$ & 110 & 100 & 38.8 & 13 & $\begin{array}{l}\text { Patients evaluated at a TMD clinic } \\
\text { and enrolled in a RCT; USA }\end{array}$ & $\begin{array}{l}\mathrm{T} 1=\text { prior to } \\
\text { enrolment in } \mathrm{RCT}, \\
\text { where facial pain } \geq 3 \\
\text { months, } \mathrm{T} 2=\text { daily } \\
\text { diary for next } 14 \text { days } \\
\text { ( } 3 \text { times per day) }\end{array}$ & $\begin{array}{l}\text { Catastrophizing subscale of } \\
\text { the Coping Strategies } \\
\text { Questionnaire @ T1; brief } \\
\text { daily diary measure of } \\
\text { catastrophizing/rumination } \\
\text { (3 Likert-style items) @ T2 }\end{array}$ & $\begin{array}{l}\text { Beck Depression Inventory } \\
\text { @ T1; brief daily diary } \\
\text { measure of negative mood } \\
\text { ('unhappy', 'annoyed', } \\
\text { 'anxious') @ T2 }\end{array}$ \\
\hline 25 & $\begin{array}{l}\text { Hanley et al. (2004), Jensen et } \\
\text { al. (2002) }\end{array}$ & $\begin{array}{l}\text { Phantom limb } \\
\text { pain }\end{array}$ & 89 & $70^{8}$ & 44.7 & 73 & $\begin{array}{l}\text { Consecutive admissions at } \\
\text { Department of Orthopaedic } \\
\text { Surgery for lower limb amputation } \\
\text { invited to participate in RCT; USA }\end{array}$ & $\begin{array}{l}\text { T1=1 month post- } \\
\text { amputation, } \mathrm{T} 2=6 \\
\text { months post- } \\
\text { amputation, } \mathrm{T} 3=12 \\
\text { months post- } \\
\text { amputation, } \mathrm{T} 4=24 \\
\text { months post- } \\
\text { amputation }\end{array}$ & $\begin{array}{l}\text { Catastrophizing subscale of } \\
\text { the Coping Strategies } \\
\text { Questionnaire @ T1, T2, T3 } \\
\text { and T4 }\end{array}$ & $\begin{array}{l}\text { Centre for Epidemiologic } \\
\text { Studies Depression Scale @ } \\
\mathrm{T} 1, \mathrm{~T} 2, \mathrm{~T} 3 \text { and } \mathrm{T} 4\end{array}$ \\
\hline 26 & Jensen et al. (2001) & $\begin{array}{l}\text { Chronic pain } \\
\text { (mixed } \\
\text { primary sites) }\end{array}$ & 197 & 141 & 44.7 & 49 & $\begin{array}{l}\text { Patients enrolled in } \\
\text { multidisciplinary pain management } \\
\text { program; USA }\end{array}$ & $\begin{array}{l}\mathrm{T} 1=\text { pre-treatment } \\
\text { (mean pain duration } \\
3.2 \text { years), } \mathrm{T} 2=\text { post- } \\
\text { treatment (approx. } 3 \\
\text { weeks later), } \mathrm{T} 3=6 \\
\text { months later, } \mathrm{T} 4=12 \\
\text { months later }\end{array}$ & $\begin{array}{l}\text { Catastrophizing subscale of } \\
\text { the Coping Strategies } \\
\text { Questionnaire @ T1, T2, T3 } \\
\text { and T4 }\end{array}$ & $\begin{array}{l}\text { Centre for Epidemiologic } \\
\text { Studies Depression Scale @ } \\
\mathrm{T} 1, \mathrm{~T} 2, \mathrm{~T} 3 \text { and } \mathrm{T4}\end{array}$ \\
\hline 27 & Sparkes et al. (2015) & $\begin{array}{l}\text { Mixed pain } \\
\text { conditions }\end{array}$ & 75 & 56 & 47.4 & 44.6 & $\begin{array}{l}\text { Consecutive patients assessed by a } \\
\text { multidisciplinary team at a } \\
\text { secondary care centre and referred } \\
\text { for a spinal cord stimulation (SCS) } \\
\text { trial; UK }\end{array}$ & $\begin{array}{l}\mathrm{T} 1=1 \text { week before } \\
\text { SCS trial (mean pain } \\
\text { duration } 8.2 \text { years), } \\
\mathrm{T} 2=6 \text { months post- } \\
\mathrm{SCS}, \mathrm{T} 3=12 \text { months } \\
\text { post-SCS }\end{array}$ & $\begin{array}{l}\text { Catastrophizing subscale of } \\
\text { the Coping Strategies } \\
\text { Questionnaire @ T1,T2, T3 }\end{array}$ & $\begin{array}{l}\text { Hospital Anxiety \& } \\
\text { Depression Scale @ T1, T2, } \\
\text { T3 }\end{array}$ \\
\hline 28 & Mehlsen et al. (2015) & Chronic pain & 87 & 73 & 52 & 15 & $\begin{array}{l}\text { Patients Invited to attend a pain } \\
\text { self-management course by local } \\
\text { health care and social work } \\
\text { professionals (pain duration }>3 \\
\text { months); Denmark }\end{array}$ & $\begin{array}{l}\mathrm{T} 1=2-14 \text { days before } \\
\text { course; } T 2=1-3 \text { weeks } \\
\text { after course, } T 3=5-6 \\
\text { months after course }\end{array}$ & $\begin{array}{l}\text { Pain Catastrophizing Scale @ } \\
\text { T1, T2, T3 }\end{array}$ & $\begin{array}{l}\text { Depression and anxiety } \\
\text { subscales of the Common } \\
\text { Mental Disorders } \\
\text { Questionnaire @ T1, T2, T3 }\end{array}$ \\
\hline 29 & Bourgault et al. (2015) & $\begin{array}{l}\text { Fibromyalgia } \\
\text { syndrome }\end{array}$ & 58 & 37 & 50 & 7.1 & $\begin{array}{l}\text { Patients recruited via newspaper } \\
\text { adverts for a fibromyalgia self- } \\
\text { management intervention (mean } \\
\text { duration of pain }>10 \text { years); Canada }\end{array}$ & $\begin{array}{l}\text { T1=prior to } \\
\text { intervention, T2=post- } \\
\text { intervention ( } \sim 11 \\
\text { weeks), T3=3 months, } \\
\text { T4=6 months, T5=12 } \\
\text { months later }\end{array}$ & $\begin{array}{l}\text { Catastrophizing subscale of } \\
\text { the Coping Strategies } \\
\text { Questionnaire @ } 11, \mathrm{~T} 2, \mathrm{~T} 3 \text {, } \\
\mathrm{T} 4, \mathrm{~T} 5\end{array}$ & $\begin{array}{l}\text { Beck Depression Inventory } \\
@ \mathrm{~T} 1, \mathrm{~T} 2, \mathrm{~T} 3, \mathrm{~T} 4, \mathrm{~T} 5\end{array}$ \\
\hline 30 & Rzewuska et al. (2015) & Musculo- & 502 & $502^{h}$ & 64.8 & 38.6 & Consecutive older adults presenting & T1=following GP & Catastrophizing subscale of & Hospital Anxiety \& \\
\hline
\end{tabular}


${ }^{a}$ Where more than one follow-up, ' $\mathrm{N}$ analysed' refers to $\mathrm{N}$ included in appropriate analyses at final time point

${ }^{\mathrm{b}}$ Demographics (age and sex) of whole sample at baseline

'Refers to Pearsons correlations, for partial correlations $n=17$

d126 met inclusion criteria

${ }^{\mathrm{e}}$ Does not include 33 controls who participated at $\mathrm{T} 1$ but were not required to participate at $\mathrm{T} 2$

${ }_{2} 79$ met inclusion criteria

${ }^{\mathrm{g}} 61$ at $\mathrm{T} 2$

${ }^{\mathrm{h}} 392$ completers at $\mathrm{T} 4$, but all cases who completed at least one assessment were included in analyses

Abbreviations: PNT = perseverative negative thinking, $\mathrm{PCl}=$ percutaneous coronary intervention, $\mathrm{Ml}=$ myocardial infarction, $\mathrm{T} 1=$ time 1 (baseline), $\mathrm{T} 2$ = time 2 (follow-up), T3 = time 3 (follow-up), T4 = time 4 (follow-

up), T5 = time 5 (follow-up), T6 = time 6 (follow-up) 


\section{Perseverative negative thinking and negative affect}

Findings from all included studies are summarised in Table 2.

Bivariate analyses Prospective, bivariate correlations between perseverative negative thinking and subsequent depression, anxiety or emotional distress were reported in 20 of the 30 studies identified. The most commonly studied associations were of rumination (7 studies) and catastrophizing (9 studies) with depression. Eighteen studies found a significant association between perseverative negative thinking at one assessment time with depression, anxiety or emotional distress at a subsequent time. One of these studies[56] found mixed evidence of an association ( 3 out of 4 correlations significant). The 2 studies that did not find a significant association had particularly low sample sizes at follow-up ( $n=24[73]$ and $n=22[70]$ ). Bivariate effect sizes ranged between $r=.23$ and $r=.73$, representing small to moderate effects.

The significant associations did not appear to be influenced by type/measure of perseverative negative thinking, type/measure of depression, anxiety or emotional distress, or whether follow-ups took place at less than or greater than 6 months (median time to follow-up) after baseline.

Reverse-associations 7 of the 30 identified studies reported bivariate correlations between baseline depression, anxiety or emotional distress with subsequent perseverative negative thinking, and 6 of these found a significant positive association.

Multivariable analyses Multivariable analyses of the association between perseverative negative thinking with subsequent depression, anxiety or emotional distress were available for 25 of the 30 included studies and included partial correlations (4 studies), multiple regression (19 studies), and latent growth models combined with logistic regression to predict trajectories of depression and anxiety ( 2 studies). Consistent with bivariate analyses the most commonly studied associations were of rumination with depression (8 studies) and catastrophizing with depression (10 studies).

Age, sex and baseline depression (or anxiety, as appropriate) were the variables most commonly controlled for (15, 14 and 17 studies, respectively). Only 8 studies controlled for all three of these confounders (and 2 studies in entirely female samples controlled for both age and baseline depression). A variety of other demographic, disease, physical and psychosocial factors were also controlled for. 
Ten studies found significant positive associations between measures of perseverative negative thinking and subsequent depression, anxiety or emotional distress, and a further 5 showed mixed results, i.e. some associations significant but some not. Five of these studies controlled for age, sex and baseline depression, and 3 studies controlled for baseline depression alone. One study found a negative association, i.e. where high catastrophization at baseline predicted greater improvement in depression over the subsequent period.

Significant multivariable associations were found more often in studies that measured the effect of catastrophizing on subsequent depression, anxiety or emotional distress compared to studies that measured the effect of rumination. However, associations did not appear to be influenced by the measure of depression, anxiety or emotional distress used. In addition, associations did not vary according to whether follow-ups took place before or after the median time to follow-up (6 months), although significant effects were found less often in studies with particularly short (up to 1 month) and long (>1 year) followups and most frequently among studies with follow-up periods between 1 month and 1 year (although there were fewer studies with particularly short or long follow-ups).

A variety of effect sizes and coefficients were reported. Partial correlations ranged from $r=.23$ to $r=.35$. For multiple regression analyses, the contribution of perseverative negative thinking to subsequent depression, anxiety or emotional distress was indicated using $\Delta \mathrm{R}^{2}$ (range=.01 to .083 ), $\beta$ (range $=.21$ to .53 ), or $B$ (range $=.0865$ to .62 ). Odds ratios (range=1.15 to 8.75) were given for logistic regression analyses. In studies that controlled for baseline depression, anxiety or emotional distress, the range of partial correlations, $\Delta R^{2}$ and odds ratios were unchanged, however the range of $B$ was higher (range=.61 to .62; but based on only 2 observations) and $\beta$ was available for only one study with a value of .21.

Reverse-associations Only 2 studies reported multivariable analyses (multiple regression in both cases) of the association of depression, anxiety or emotional distress with subsequent perseverative negative thinking, and neither found a significant association. 
Table 2: Findings of included studies

\begin{tabular}{|c|c|c|c|c|}
\hline ID & Authors and date & Bivariate findings & Multivariable findings & Variables controlled for \\
\hline 1 & Denton et al. $(2012 ; 2011)$ & $\begin{array}{l}\text { T1 rumination correlates with T2 depression }(r=.49, \\
p<.001) ; T 1 \text { depression correlates with } T 2 \text { rumination } \\
(r=.52, p<.001)\end{array}$ & $\begin{array}{l}\text { T1 rumination predicts } T 2 \text { depression independently }\left(\Delta R^{2}=.01, \Delta F=9.21, p=.003\right) \text { and in } \\
\text { interaction with poor dyadic adjustment }\left(\Delta R^{2}=.01, \Delta F=2.67, p=.03\right) \\
\text { In patients depressed at baseline } T 1 \text { rumination independently predicts } T 2 \text { depression }\left(\Delta R^{2}=\right. \\
0.03, \Delta F=6.65, p=0.01) \\
\text { In patients non-depressed at baseline T1 rumination does not independently predict } T 2 \\
\text { depression }\left(\Delta R^{2}=.002, \Delta F=.80, p=.37\right) \text {, but T1 rumination predicts } T 2 \text { depression in interaction } \\
\text { with poor dyadic adjustment }\left(\Delta R^{2}=.06, \Delta F=5.31, p<0.001\right)\end{array}$ & $\begin{array}{l}\text { Age, sex, partner, years of schooling, } \\
\text { work status, ethnicity, baseline } \\
\text { depression, Charlson comorbidity } \\
\text { index, cardiac disease severity }\end{array}$ \\
\hline 2 & Garnefski \& Kraaij (2010) & $\begin{array}{l}\text { T1 rumination correlates with } \mathrm{T} 2 \text { depression }(\mathrm{r}=.43 \\
\mathrm{p}<.001) ; \mathrm{T} 1 \text { catastrophizing correlates with } \mathrm{T} 2 \text { depression } \\
(\mathrm{r}=.45, \mathrm{p}<.001)\end{array}$ & T1 rumination/catastrophizing predicts $T 2$ depression $(\beta=.35, p<.001)$ & Sex, age, physical limitations \\
\hline 3 & Vogele et al. (2012) & $\begin{array}{l}\text { T1 rumination does not correlate with depression at } \mathrm{T} 2 \\
(\mathrm{r}=.01, \mathrm{~ns}) \text { or } \mathrm{T} 3(\mathrm{r}=.14, \mathrm{~ns})\end{array}$ & $\mathrm{T} 1$ rumination does not correlate with depression at $\mathrm{T} 2(\mathrm{r}=.10, \mathrm{~ns})$ or $\mathrm{T} 3(\mathrm{r}=.24, \mathrm{~ns})$ & Baseline depression \\
\hline 4 & Baker (2014) & $\begin{array}{l}\text { T1 rumination correlates with } \mathrm{T} 2 \text { depression }(\mathrm{r}=.73 \\
\mathrm{p}=.01) ; \mathrm{T} 1 \text { depression correlates with } \mathrm{T} 2 \text { rumination } \\
(\mathrm{r}=.70, \mathrm{p}=.01)\end{array}$ & T1 rumination predicts T2 depression ( $\beta=.46, B=.202, S E=.043, t=4.705, p<.001, R^{2}=.083$ ) & $\begin{array}{l}\text { Baseline depression, cardiac quality } \\
\text { of life, age, sex, body mass index, } \\
\text { social support }\end{array}$ \\
\hline 5 & Xiao et al. (2011) & $\begin{array}{l}\text { Greater rumination at T1 correlates with greater } \\
\text { depression at } \mathrm{T} 2(r=.38, p<.001) \text {; greater catastrophizing } \\
\text { at T1 correlates with greater depression at T2 }(r=.37 \text {, } \\
p<.001)\end{array}$ & $\begin{array}{l}\text { Higher T1 rumination ( } \mathrm{B}=.62, \mathrm{t}=0.18, \mathrm{p}<.001) \text { and T1 catastrophizing }(\mathrm{B}=.61, \mathrm{t}=.18, \mathrm{p}<.001) \\
\text { predicts increases in } \mathrm{T} 2 \text { depressive symptoms }\end{array}$ & $\begin{array}{l}\text { Sex, baseline depression, smoking, } \\
\text { alcohol use, coffee consumption }\end{array}$ \\
\hline 6 & Keefe et al. (1989) & $\begin{array}{l}\text { T1 catastrophizing correlates with } \mathrm{T} 2 \text { depression }(r=.62 \text {, } \\
p<.01)\end{array}$ & T1 catastrophizing predicts $\mathrm{T} 2$ depression $\left(\mathrm{sr}^{2}=.043, \mathrm{~F}=20.87, \mathrm{p}=<.001\right)$ & $\begin{array}{l}\text { Baseline depression, age, SES, sex, } \\
\text { disability support status, duration of } \\
\text { disease }\end{array}$ \\
\hline 7 & Sturgeon \& Zautra (2013) & Bivariate analyses not reported & $\begin{array}{l}\text { Previous day catastrophizing predicts subsequent day depressive symptoms }(B=.0865, p<.05) \text { but } \\
\text { not negative affect }(B=.0016, n s)\end{array}$ & $\begin{array}{l}\text { Age, sex, neuroticism, positive affect } \\
\text { (negative affect analysis only) }\end{array}$ \\
\hline 8 & Schiaffano \& Revenson (1995) & $\begin{array}{l}\text { T1 depression correlates with } \mathrm{T} 2 \text { rumination }(\mathrm{r}=.30, \\
\mathrm{p}<.05)\end{array}$ & $T 1$ depression does not predict $T 2$ rumination $\left(\beta=.22, \Delta \mathrm{R}^{2}=.05, \mathrm{~F}=2.84, \mathrm{p}<.10\right)$ & Education \\
\hline 9 & Sharpe et al. $(2001)^{b}$ & $\begin{array}{l}\text { T1 catastrophizing does not correlate with T2 } \\
\text { depression }(r=.18, p=.461) \text {, T6 depression }(r=.03, p=.891) \text {, } \\
\text { T2 anxiety }(r=.32, p=.177) \text { or } \mathrm{T} 6 \text { anxiety }(r=.12, p=.607)\end{array}$ & $\mathrm{T} 1$ catastrophizing does not correlate with $\mathrm{T} 2$ depression $(\mathrm{r}=.11, \mathrm{p}=.671)$ or anxiety $(\mathrm{r}=.34, \mathrm{p}=.17)$ & $\begin{array}{l}\text { Age, baseline depression, baseline } \\
\text { anxiety }\end{array}$ \\
\hline 10 & Wang et al. (2014) & Bivariate analyses not reported & $\begin{array}{l}\text { T1 rumination }(\beta=.09, \mathrm{SE}=0.12, \mathrm{~ns}) \text { and catastrophizing }(\beta=.26, \mathrm{SE}=.15, \mathrm{~ns}) \text { do not predict T2 } \\
\text { depression }\end{array}$ & $\begin{array}{l}\text { Age, place of residence, marital } \\
\text { status, years of schooling, } \\
\text { employment status, disease severity, } \\
\text { baseline depression }\end{array}$ \\
\hline 11 & Andreu et al. (2012) & $\begin{array}{l}\text { T4 anxious preoccupation does not correlate with T1 (- } \\
.08, \mathrm{~ns}), \mathrm{T} 2(-.04, \mathrm{~ns}) \text { or T3 }(.02, \mathrm{~ns}) \text { distress }\end{array}$ & Multivariable analyses not reported & None \\
\hline 12 & Ferrero et al. (1994) & $\begin{array}{l}\text { T1 anxious preoccupation does not correlate with } \mathrm{T} 2 \\
\text { distress }(r=.21, \mathrm{~ns}) \text { but does correlate with } \mathrm{T} 3 \text { distress } \\
(\mathrm{r}=.40, \mathrm{p}<.001) ; \mathrm{T} 2 \text { anxious preoccupation correlates with }\end{array}$ & $\begin{array}{l}\text { T1 anxious preoccupation does not predict } T 2 \text { or } T 3 \text { distress (relevant regression statistics not } \\
\text { reported) } \\
T 2 \text { anxious preoccupation predicts } T 3 \text { distress (full model } R^{2}=.428, p<.001 \text {, including predictors }\end{array}$ & Baseline distress, physical symptoms \\
\hline
\end{tabular}




\begin{tabular}{ll}
\hline $13 \quad$ Groarke et al. (2013) & $\begin{array}{l}\text { T1 anxious preoccupation correlates with T2 depression } \\
(\mathrm{r}=.23, \mathrm{p}<.001) \text { and } \mathrm{T} 2 \text { anxiety }(\mathrm{r}=.35,<.001)\end{array}$
\end{tabular}

$14 \quad$ Lam et al. (2013)
1 anxious preoccupation does not predict $\mathrm{T} 2$ depression $(\beta=.014, \mathrm{~B}=.010, \mathrm{SE}(\mathrm{B})=.048, \mathrm{t}=.216$ $\left.\Delta \mathrm{R}^{2}=.000, \Delta \mathrm{F}=.046, \mathrm{p}=.830\right), \mathrm{T} 2$ anxiety $\left(\beta=.038, \mathrm{~B}=.036, \mathrm{SE}(\mathrm{B})=.058, \mathrm{t}=.617, \Delta \mathrm{R}^{2}=.001, \Delta \mathrm{F}=.381\right.$ $\mathrm{p}=.538$ ) or T2 negative affect $\left(\beta=.022, \mathrm{~B}=.041, \mathrm{SE}(\mathrm{B})=.121, t=.340, \Delta \mathrm{R}^{2}=.000, \Delta \mathrm{F}=.115, \mathrm{p}=.734\right)$ Four coping-related factors including negative cancer-related rumination differentiated depression $\left(x 2(8)=132.83, \mathrm{p}<.001, \mathrm{R}^{2}=.52\right)$ and anxiety $\left(x 2(12)=107.00, \mathrm{p}<.001, \mathrm{R}^{2}=.45\right)$ trajectories. T1 rumination greater in 'High-stable/high-recovering' ( $\mathrm{OR}=1.38(95 \% \mathrm{Cl}=1.18-1.61)$ $\mathrm{p}<.001$ ) and 'Recovering' ( $\mathrm{OR}=1.15(95 \% \mathrm{Cl}=1.03-1.30), \mathrm{p}=.017)$ trajectories compared to lowdepression referent group. T1 rumination greater in 'High-stable' (OR $=1.22(95 \% \mathrm{Cl}=1.06-1.39)$, $\mathrm{p}=.005)$ and 'Recovering' ( $\mathrm{OR}=1.18(95 \% \mathrm{Cl}=1.04-1.34), \mathrm{p}=.012)$, but not 'Intermediate', trajectories compared to low-anxiety referent group.

\begin{tabular}{lll}
\hline 15 & Thomsen et al. (2013) & $\begin{array}{l}\text { T1 rumination correlates with T2 depression ( } \mathrm{r}=.32, \\
\mathrm{p}<.05 .) ; \mathrm{T} 1 \text { depression correlates with } \mathrm{T} 2 \text { rumination } \\
(\mathrm{r}=.37, \mathrm{p}<.05 .)\end{array}$ \\
\hline 16 & Couper et al. (2010) & Bivariate analyses not reported
\end{tabular}

1 rumination does not predict $\mathrm{T} 2$ depression $(\beta=.07, \mathrm{~ns})$

T1 anxious preoccupation does not predict T2 depression (early $\beta=N R$, ns; advanced $\beta=.15$, ns) $\mathrm{T} 1$ anxious preoccupation does not predict T2 anxiety in early ( $\beta=\mathrm{NR}, \mathrm{ns})$, but does predict anxiety in late prostate cancer $(\beta=.21, p<.001)$

\begin{tabular}{lll}
\hline 17 & Lehto \& Cimprich (2009) $^{\mathrm{b}}$ & $\begin{array}{l}\text { Worry at T1 correlates with state anxiety at T2 ( } \mathrm{r}=.34, \\
\mathrm{p}=.027)\end{array}$ \\
\hline 18 & Lampic et al. (1994) & $\begin{array}{l}\mathrm{T} 2 \text { anxious preoccupation correlates with T3 anxiety } \\
(\mathrm{r}=.31, \mathrm{p}<.01)\end{array}$ \\
\hline 19 & Vollmer et al. (2011) & $\begin{array}{l}\mathrm{T} 1 \text { preoccupation with death correlates with T2 } \\
\text { depression }(\mathrm{r}=.37, \mathrm{p}=.013) \text { and anxiety }(\mathrm{r}=.38, \mathrm{p}=.012) ; \mathrm{T} 1 \\
\text { depression }(\mathrm{r}=.42, \mathrm{p}=.009) \text { and anxiety }(\mathrm{r}=.44, \mathrm{p}=.006) \\
\text { correlates with T2 preoccupation with death }\end{array}$ \\
&
\end{tabular}

$20 \quad$ Kraaij et al. (2008)

T1 rumination correlates with $\mathrm{T} 2$ depression $(\mathrm{r}=.29$, $\mathrm{p}<.001) ; \mathrm{T} 1$ catastrophizing correlates with $\mathrm{T} 2$ depression $(\mathrm{r}=.31, \mathrm{p}<.001)$

T1 rumination / catastrophizing correlates with depression $(r=.37, p<.001)$ and anxiety $(r=.40, p<.001)$ at $\mathrm{T} 2$

$21 \quad$ Kraaij et al. (2010)

23$$
24
$$

Hanley et al. (2004), Jensen et
al. (2002)

Change (T2-T1) in catastrophizing correlates with change in psychological functioning $(r=.25, p<.01)$ Change (T2-T1) in catastrophizing correlates with change in depression $(r=.49, p<.001)$

T1 depression correlates with $\mathrm{T} 2$

catastrophizing/rumination $(r=.39, \mathrm{p}<.0001)$

Multivariable analyses not reported

Multivariable analyses not reported

$\mathrm{T} 1$ preoccupation with death does not predict $\mathrm{T} 2$ depression $\left(\Delta \mathrm{R}^{2}=.004, \Delta \mathrm{F}=.301, \mathrm{p}=.586\right)$ or $\mathrm{T} 2$ anxiety $\left(\Delta R^{2}=.010, \Delta F=.670, p=.418\right)$

$\mathrm{T} 1$ depression $\left(\Delta \mathrm{R}^{2}=.002, \Delta \mathrm{F}=.114, \mathrm{p}=.738\right)$ and $\mathrm{T} 1$ anxiety $\left(\Delta \mathrm{R}^{2}<.000, \Delta \mathrm{F}=.021, \mathrm{p}=.887\right)$ does not predict T2 preoccupation with death (after controlling for age, sex, and T1 preoccupation with death)

T1 rumination does not predict T2 depressive symptoms (test statistics not reported)

$\mathrm{T} 1$ catastrophizing predicts increased depressive symptoms at $\mathrm{T} 2(\beta=.26, \mathrm{p}<.05)$

T1 rumination/catastrophizing predicts T2 depression $(\beta=.26, p<.05)$ and T2 anxiety $(\beta=.24$ $\mathrm{p}<.05)$

Change (T2-T1) in catastrophizing does not predict change in psychological functioning $(\beta=.18$, ns)

Baseline depression/anxiety, age, disease severity, type of surgery

Radiation therapy and occupational status (depression model only)

Age, baseline depression

Baseline depression, health-related quality of life

None

None

Age, sex, baseline depression (or anxiety as appropriate)

Sex, wish to have children

Sex, number of children, time since treatment, success of treatment

Pain intensity

None

Daily catastrophizing/rumination at previous time point does not predict daily negative mood at subsequent time point ( $\mathrm{B}=.05, \mathrm{~ns})$

Greater T1 catastrophizing predicts improvements in depression from T1 to T2 ( $\beta=.53, p<.001)$,

Baseline negative mood

from T1 to T3; $\beta=.46, p<.01$ ) and from T1 to T4; $\beta=.43, \mathrm{p}<.05)$

Change in catastrophizing predicts change in depression (T1-T2 $\beta=.44, p<.001$; T1-T3 $\beta=.48$,
Pain intensity, age, sex Baseline pain intensity 


\begin{tabular}{|c|c|c|c|c|}
\hline & & $\begin{array}{l}\text { depression (T1-T2 r=.64, } p<.001 ; \mathrm{T} 1-\mathrm{T} 3 \mathrm{r}=.61, \mathrm{p}<.001 ; \mathrm{T} 1- \\
\mathrm{T} 4 \mathrm{r}=.53, \mathrm{p}<.001)\end{array}$ & $\mathrm{p}<.001 ; \mathrm{T} 1-\mathrm{T} 4 \beta=.38, \mathrm{p}<.001)$ & \\
\hline 27 & Sparkes et al. $(2015)^{b}$ & $\begin{array}{l}\text { T1 catastrophizing correlates with } \mathrm{T} 2(\mathrm{r}=.55, \mathrm{p}<.01) \text { and } \\
\mathrm{T} 3(\mathrm{r}=.57, \mathrm{p}<.01) \text { depression, and with } \mathrm{T} 2(\mathrm{r}=.51, \mathrm{p}<.01) \\
\text { and } \mathrm{T} 3(\mathrm{r}=.42, \mathrm{p}<.01) \text { anxiety }\end{array}$ & $\begin{array}{l}\text { T1 catastrophizing correlates with T2 depression }(r=.30, p=.026) \text {, T3 depression }(r=.35, p=.009) \text {, } \\
\text { T2 anxiety }(r=.31, p=.02) \text { but not } \mathrm{T} 3 \text { anxiety }(r=.21, p=.119)\end{array}$ & Age, gender, baseline depression \\
\hline 28 & Mehlsen et al. (2015) $)^{b}$ & Bivariate analyses not reported & $\begin{array}{l}\text { T1 catastrophizing correlated with T2 }(r=.23, p=.018) \text { and } \mathrm{T} 3(r=.24, p=.014) \text { depression, and with } \\
\mathrm{T} 2(r=.24, \mathrm{p}=.015) \text { and } \mathrm{T} 3(\mathrm{r}=.31, \mathrm{p}=.001) \text { anxiety }\end{array}$ & Age, gender, baseline depression \\
\hline 29 & Bourgault et al. $(2015)^{b}$ & $\begin{array}{l}\text { T1 catastrophizing correlates with } \mathrm{T} 2(\mathrm{r}=.27, \mathrm{p}=.0002) \\
\text { and } \mathrm{T} 3(\mathrm{r}=.29, \mathrm{p}=.0002) \text { depression }\end{array}$ & $\mathrm{T} 1$ catastrophizing does not predict $\mathrm{T} 2(\beta=.35, \mathrm{p}=.3562)$ or $\mathrm{T} 3(\beta=-.04, \mathrm{p}=.9231)$ depression & $\begin{array}{l}\text { Age, gender, baseline depression, } \\
\text { treatment arm }\end{array}$ \\
\hline 30 & Rzewuska et al. (2015) & Bivariate analyses not reported & $\begin{array}{l}\text { T1 catastrophizing differentiated depression- and anxiety-related trajectories over } 12 \text { months. } \\
\text { T1 catastrophizing greater in 'persistent depression' group compared to 'no depression' referent } \\
\text { group (adj. OR=3.20 ( } 95 \% \mathrm{Cl}=1.53-6.66)) \text {. No significant difference between 'depression } \\
\text { symptom recovery' group and 'no depression' referent group. } \\
\text { T1 catastrophizing greater in 'persistent anxiety' (adj. OR=8.75 ( } 95 \% \mathrm{Cl}=3.66-20.89) \text { ) and } \\
\text { 'transient anxiety' (adj. OR=4.09 ( } 95 \% \mathrm{Cl}=1.38-12.13) \text { ) groups compared to 'no anxiety' referent } \\
\text { group. }\end{array}$ & $\begin{array}{l}\text { Age (depression model only), gender, } \\
\text { baseline depression/anxiety, coping } \\
\text { strategies, emotional support, pain- } \\
\text { related variables }\end{array}$ \\
\hline
\end{tabular}

${ }^{\mathrm{b}}$ Based on additional analyses provided by the authors

Abbreviations: SES=socioeconomic status, T1 = time 1 (baseline), T2 = time 2 (follow-up), T3 = time 3 (follow-up), T4 = time 4 (follow-up), T5 = time 5 (follow-up), T6 = time 6 (follow-up), NR=not reported 


\section{Long term conditions}

Studies reporting multivariable associations were grouped according to LTC (see Appendix C; supplementary material).

In heart disease and chronic pain the majority of studies reported significant associations between perseverative negative thinking and depression, anxiety or emotional distress. In rheumatoid arthritis and infertility there was mixed evidence of an association between perseverative negative thinking and depression, anxiety or emotional distress. The majority of studies in cancer patients did not find an association between perseverative negative thinking and depression, anxiety or emotional distress. In one small study there was no evidence of an association between perseverative negative thinking and depression, anxiety or emotional distress in patients with muscular dystrophy.

\section{Physical outcomes}

Associations between perseverative negative thinking and physical outcomes (such as health-related quality of life, functional limitations, pain intensity and pain interference) were reported in 9 studies[52, 59-63, 68, 69, 71, 72]. Four studies found evidence of an association, 1 study found mixed evidence, and 4 studies found no evidence of an association. Rumination was not related to subsequent quality of life or functional disability. Catastrophizing was associated with impairments in physical outcomes, improvements in physical outcomes, and in some studies was not associated with physical outcomes.

\section{Reporting bias}

23 studies reported the results of bivariate analyses, and of those multivariable analyses were also available for 19 studies. Significant bivariate associations were found in $89 \%$ of the 19 studies for which both types of analyses were available, and ranged between $r=.23$ to $r=.73$. In the 4 studies for which multivariable findings were not available, significant bivariate associations were found less frequently (75\% of the studies) and the range of effect sizes was smaller ( $r=.31$ to $r=.49)$. This hints at a possible bias toward reporting multivariable analyses where significant or large associations were most likely to be found, although this suggestion is based on only 4 observations. 


\section{Risk of bias}

Component and global risk of bias ratings for each study are presented in Table 3. Based on global ratings, 23 of the included studies were moderate quality and 7 were weak quality. Studies with overall moderate ratings were not all equivalent; 5 studies were assigned 3 strong component ratings and these were comparatively good quality[52, 55, 75 , $76,79]$ with particular strengths in retention of participants at follow-up (>80\%), control for appropriate confounders, and reliability/validity of data collection methods. Four of these 5 studies found significant associations between perseverative negative thinking and subsequent depression, anxiety or emotional distress after controlling for relevant confounders including baseline depression.

Among the overall weak quality studies, selection bias and retention of participants were identified as areas of concern. In multivariable analyses associations between perseverative negative thinking and subsequent depression, anxiety or emotional distress were found less often in studies of weak methodological quality.

In heart disease and chronic pain, studies which did not find an effect had small sample sizes at follow-up $[73,77]$, or used unusual methods to collect or analyse data (time series data and use of change scores[72]).

In rheumatoid arthritis, where evidence of an association was weak, studies tended to be of weak quality due to low sample sizes, high numbers of withdrawals at follow-up, and limited reliability of measures. Similarly, there was weak evidence of an association in people experiencing infertility and these studies tended to be weak quality due to use of self-selected samples and high numbers of withdrawals.

Studies in cancer patients, in whom evidence of an association between perseverative negative thinking and depression, anxiety or emotional distress was weak, recruited quite heterogeneous participants and, unlike other studies, focussed on 'anxious preoccupation' and 'preoccupation with death', which may have influenced findings. 
Table 3: Risk of bias/quality assessment

\begin{tabular}{|c|c|c|c|c|c|c|c|c|}
\hline ID & Authors and date & Selection bias & Design $^{a}$ & Confounding & Blinding $^{\mathrm{b}}$ & Data collection & Withdrawals & Global rating \\
\hline 1 & Denton et al. $(2012,2011)$ & 2 & 2 & 1 & 2 & 1 & 1 & 2 \\
\hline 2 & Garnefski \& Kraaij (2010) & 2 & 2 & 2 & 2 & 1 & 3 & 2 \\
\hline 3 & Vogele et al. (2012) & 3 & 2 & 2 & 2 & 1 & 3 & 3 \\
\hline 4 & Baker (2014) & 2 & 2 & 1 & 2 & 1 & 1 & 2 \\
\hline 5 & Xiao et al. (2011) & 1 & 2 & 2 & 2 & 1 & 1 & 2 \\
\hline 6 & Keefe et al. (1989) & 3 & 2 & 1 & 2 & 1 & 3 & 3 \\
\hline 7 & Sturgeon \& Zautra (2013) & 3 & 2 & 2 & 2 & 3 & 3 & 3 \\
\hline 8 & Schiaffano \& Revenson (1995) & 2 & 2 & 3 & 2 & 3 & 2 & 3 \\
\hline 9 & Sharpe et al. (2001) & 2 & 2 & 2 & 2 & 1 & 3 & 2 \\
\hline 10 & Wang et al. (2014) & 2 & 2 & 1 & 2 & 1 & 1 & 2 \\
\hline 11 & Andreu et al. (2012) & 2 & 2 & 3 & 2 & 1 & 1 & 2 \\
\hline 12 & Ferrero et al. (1994) & 2 & 2 & 2 & 2 & 1 & 1 & 2 \\
\hline 13 & Groarke et al.(2013) & 3 & 2 & 1 & 2 & 1 & 2 & 2 \\
\hline 14 & Lam et al. (2013) & 2 & 2 & 3 & 2 & 1 & 1 & 2 \\
\hline 15 & Thomsen et al. (2013) & 2 & 2 & 2 & 2 & 1 & 1 & 2 \\
\hline 16 & Couper et al. (2010) & 2 & 2 & 2 & 2 & 1 & 2 & 2 \\
\hline 17 & Lehto \& Cimprich (2009) & 2 & 2 & 3 & 2 & 1 & 1 & 2 \\
\hline 18 & Lampic et al. (1994) & 2 & 2 & 3 & 2 & 1 & 2 & 2 \\
\hline 19 & Vollmer et al. (2011) & 2 & 2 & 1 & 2 & 1 & 3 & 2 \\
\hline 20 & Kraaij et al. (2008) & 3 & 2 & 2 & 2 & 1 & 3 & 3 \\
\hline 21 & Kraaij et al. (2010) & 3 & 2 & 2 & 2 & 1 & 3 & 3 \\
\hline 22 & Nieto et al. (2012) & 3 & 2 & 3 & 2 & 1 & 3 & 3 \\
\hline 23 & Jensen et al. (2006) & 2 & 2 & 3 & 2 & 1 & 1 & 2 \\
\hline 24 & Turner et al. (2004) & 3 & 2 & 2 & 2 & 1 & 1 & 2 \\
\hline 25 & $\begin{array}{l}\text { Hanley et al. (2004), Jensen et } \\
\text { al. (2002) }\end{array}$ & 2 & 2 & $2^{c}$ & 2 & 1 & 2 & 2 \\
\hline 26 & Jensen et al. (2001) & 2 & 2 & 3 & 2 & 1 & 2 & 2 \\
\hline 27 & Sparkes et al. (2015) & 2 & 2 & 1 & 2 & 1 & 2 & 2 \\
\hline 28 & Mehlsen et al. (2015) & 2 & 2 & 1 & 2 & 1 & 1 & 2 \\
\hline 29 & Bourgault et al. (2015) & 3 & 2 & 1 & 2 & 1 & 2 & 2 \\
\hline 30 & Rzewuska et al. (2015) & 2 & 2 & 3 & 2 & 1 & 2 & 2 \\
\hline
\end{tabular}

$1=$ strong $2=$ moderate and 3 weak

${ }^{a}$ All studies were rated as moderate quality on the study design component. There was 1 RCT[77] which would have qualified for a strong quality rating, however because the data extracted for this review related to changes in the whole cohort over several assessment times this study was treated as a cohort study for the purpose of quality assessment for this component

${ }^{b}$ The blinding component was modified to be more suitable for the included study designs, although it remained difficult to assign ratings for this component and all studies were rated as moderate quality as it was

not possible to tell if the researcher was exposed to information about the participant that could lead to bias, or if the participants were aware of the research question

c Jensen et al. $=3$ (no control for confounders at 6 month follow-up), and Hanley et al. = 2 (control for some confounders at 12 and 24 months follow-up) 


\section{Discussion}

We conducted a systematic review to clarify among people with LTCs the temporal relationship between perseverative negative thinking, on the one hand, and depression, anxiety or emotional distress, on the other, and to determine the strength of the prospective associations. Findings were limited mainly to the association of rumination and/or catastrophizing with subsequent depression. The majority of uncontrolled studies showed an association between measures of perseverative negative thinking and subsequent depression, anxiety or emotional distress. Studies controlling for the effects of covariates, including depression at baseline, using multivariable analysis showed more mixed results, though the majority of studies (15 / 25 studies) still supported a significant association, with effects being small in magnitude.

Strongest associations were observed in studies measuring catastrophizing. The strength of association between perseverative negative thinking and subsequent depression, anxiety or emotional distress appeared to vary across studies of different LTCS, with greatest effects seen in people with heart disease and chronic pain. Whilst degrees of perseverative negative thinking and of depression, anxiety or emotional distress might reasonably be expected to vary across long term conditions, it isn't immediately obvious why the relationship between such thinking and depression, anxiety or emotional distress should vary between LTCs. It is possible that some of the variability between LTCs could be due to the use of different perseverative negative thinking constructs in the different samples (e.g. studies in pain conditions tended to measure pain catastrophizing, studies in cancer patients tended to measure anxious preoccupation and preoccupation with death). The different measures are likely to reflect different dimensions of repetitive thinking, suggesting that some dimensions are important predictors of depression, anxiety or emotional distress while others are not.

Contrary to expectation, one study found that greater catastrophizing at baseline predicted improvements in depression from baseline to 6, 12 and 24 month follow-ups. Baseline catastrophizing was concurrently associated with higher levels of depression in this study, as might be expected. Since the authors did not control for the effects of depression at baseline, this counter-intuitive finding may have arisen because individuals with high 
levels of catastrophizing (and therefore also depression) at baseline had more potential for improvement in depression during follow-up.

Too few studies investigated the association of baseline depression, anxiety or emotional distress with subsequent perseverative negative thinking to be able to draw firm conclusions about the reverse association. Among the studies identified, few included measures of physical health outcome, and findings from those studies were very mixed.

The quality of studies identified was highly variable, with no "strong" studies being identified. Quality was most frequently low due to studies failing to control adequately for potential confounding variables or due to high numbers of participants dropping-out, which reduced the generalisability of findings. Interestingly, we found significant associations least frequently in the studies rated as weak compared to studies rated moderate, suggesting that poor control for confounders did not increase the likelihood of an association being found in studies identified for this review. A number of studies had small sample sizes and the majority of such studies failed to find an association between perseverative negative thinking and subsequent depression, anxiety or emotional distress. There was significant variation in study quality across LTCs.

This systematic review is the first to investigate the prospective association of perseverative negative thinking with subsequent depression, anxiety or emotional distress specifically in people with LTCs. The main strengths of this review are that it adhered to established guidelines $[44,45]$ to ensure rigorous methods were used. A comprehensive search strategy was used, combined with supplementary backward and forward citation searches of included papers. In addition, we are confident that our strategy of handsearching records for LTCs ensured that all studies containing relevant samples were identified. We did not apply a priori restrictions to the definition of LTCs. The group of conditions identified was heterogeneous and this may have contributed to the heterogeneity of findings although it is unclear whether variations in study quality across different LTC groups may explain this observation. Eligibility screening, data extraction and quality assessment were undertaken by two reviewers to minimise bias and maximise reliability. Since we were interested in clarifying the temporal relationships between perseverative negative thinking and depression, anxiety or emotional distress, we included studies investigating prospective associations in either direction. 
There are some limitations of this systematic review. First, the majority of this review is based on published journal articles so the conclusions are vulnerable to the effects of publication bias. We did find some suggestion of publication bias, in that studies presenting multivariable findings were more likely to have larger bivariate associations, compared to those that did not present multivariable findings. Second, we did not perform meta-analysis due to the multitude of measures of both perseverative negative thinking and depression, anxiety or emotional distress, and also due to heterogeneity in research methods used (including variables controlled for, and study quality). Rather, we synthesised our findings using vote counts, which is a crude method of synthesis and does not take account of the effect sizes or precision of individual studies. Conducting a meta-analysis using only studies presenting bivariate analyses would have allowed us to synthesize a subset of more comparable studies. However this would have lead to an overestimate of the associations since important confounding variables would not have been controlled for. Third, we presented findings for associations of perseverative negative thinking with physical health outcomes, such as quality of life, where these were presented within the eligible papers. However, we acknowledge that our searches were not designed to identify all such studies, since investigating the impact on physical health outcomes was not a primary objective of our review. There are likely to be other studies relevant to this objective that were not identified by our search processes. As a consequence, no firm conclusion on the association of perseverative negative affect and physical health outcomes can be drawn from our review.

We interpret the findings of our review as indicating that perseverative negative thinking (particularly catastrophizing) is prospectively associated with a range of subsequent negative affective states among people with LTCs, even after controlling for important covariates such as depression at baseline. Evidence of perseverative negative thinking predicting subsequent adverse medical outcomes in the studies identified was too mixed to enable firm conclusions. There was no convincing evidence that depression, anxiety or emotional distress predicted subsequent perseverative negative thinking, particularly after controlling for covariates.

Our findings are consistent with perseverative negative thinking causing depression, anxiety or emotional distress among people with LTCS, but current evidence falls short of proving causation. Perseverative negative thinking has been described within the context of 
a number of theoretical models, and these models offer either overt or implicit suggestions as to how perseverative negative thinking could lead to depression. The Response Styles Theory[21] posits that perseverative negative thinking (in particular depressive rumination) could lead to depression via several mechanisms including focusing attention on and elaboration of negative thoughts, interfering with problem solving, reducing motivation to engage in constructive behaviours, and eroding social support. On the other hand control theory approaches $[83,84]$ emphasize managing discrepancies between actual and desired states. This suggests that perseverative negative thinking could lead to depression when it is not possible to reduce such discrepancies (either by making progress toward, or changing, the desired state) because the discrepancy focuses attention on the unresolved issue and makes it more salient. These models of perseverative negative thinking were not developed specifically with people with chronic physical illnesses in mind, and previous research has tended to focus on otherwise healthy individuals, and so it is unclear to what extent these models apply to people with LTCs.

There did not appear to be any variation in findings based on whether follow-up took place before or after the median follow-up time of 6 months. However, closer inspection suggested that effects were identified more often in studies with intermediate length follow-up. This variation with length of follow-up could be due to significant changes in the status of the LTC or due to fluctuations in levels of perseverative negative thinking over time. Future studies should carefully consider the length of follow-up or risk missing a true association. It seems most likely that a follow-up between 1 and 12 months would be most appropriate.

The results of this review are consistent with the findings of previous narrative ([20, $23,25])$ and systematic $([22,24])$ reviews focussed on physically healthy individuals. Similar to ours, these previous reviews noted that, compared to the results of cross-sectional studies, the findings from prospective research are more mixed although the majority of such studies did support an association. In these previous reviews, moderators of the association between perseverative negative thinking and subsequent symptoms of depression and anxiety or negative affect that relate to characteristics of the population (e.g. gender, psychopathology) and to aspects of repetitive thinking itself (e.g. valence, content) have been suggested to explain some of the variability in findings. 
Further high quality research is required to clarify the association of perseverative negative thinking, on the one hand, with psychological and other medical outcomes such as quality of life, morbidity and mortality, on the other. Experimental studies in which perseverative negative thinking is induced or interrupted, with effects on depression, anxiety or emotional distress monitored, would provide good evidence of a causal association and indicate that perseverative negative thinking is a relevant target for treatment of depression and other psychological outcomes in people with LTCs. Future prospective and experimental research should investigate differences of associations of perseverative negative thinking with depression, anxiety or emotional distress in groups of individuals with different LTCs. In addition, attempts should be made to clarify mechanisms that might explain how and why perseverative negative thinking contributes to depression, anxiety and emotional distress. A number of possible mechanisms have been suggested in the research literature, including via a reduction in social support, impairment of problem solving, reduced motivation to perform positive instrumental behaviours and increased negative thinking[20,21]. These mechanisms could also provide potential targets for intervention aimed at improving depression and also physical health outcomes.

\section{Competing interests}

The authors declare that they have no competing interests.

\section{Acknowledgements}

This research was supported by the National Institute for Health Research (NIHR) Collaboration for Leadership in Applied Health Research and Care South West Peninsula at the Royal Devon and Exeter NHS Foundation Trust. The views expressed are those of the author(s) and not necessarily those of the NHS, the NIHR or the Department of Health. This research was also supported by a University of Exeter Medical School PhD Studentship awarded to Leanne Trick. We would like to thank Sarah Harris for assistance with eligibility screening. We would also like to extend our thanks to all authors who responded to reprint requests and queries, and we gratefully acknowledge the following authors for kindly providing additional data and reports: Tanja Vollmer, Marc Wittman, Rebecca Lehto, 
AnnMarie Groarke, Mimi Mehlsen, Anais Lacasse, Rui Duarte, Louise Sharpe, and Laura

Baker.

\section{$\underline{\text { References }}$}

1. DepartmentofHealth, Long term conditions compendium of information. 3rd Edition. 2012.

2. Egede, L.E., Major depression in individuals with chronic medical disorders: prevalence, correlates and association with health resource utilization, lost productivity and functional disability. General Hospital Psychiatry, 2007. 29(5): p. 409-416.

3. Clarke, D.M. and K.C. Currie, Depression, anxiety and their relationship with chronic diseases: a review of the epidemiology, risk and treatment evidence. Medical Journal of Australia, 2009. 190(7): p. S54.

4. Barth, J., M. Schumacher, and C. Herrmann-Lingen, Depression as a risk factor for mortality in patients with coronary heart disease: a meta-analysis. Psychosomatic Medicine, 2004. 66(6): p. 802-813.

5. Meijer, A., et al., Prognostic association of depression following myocardial infarction with mortality and cardiovascular events: a meta-analysis of 25 years of research. General Hospital Psychiatry, 2011. 33(3): p. 203-216.

6. Van Melle, J.P., et al., Prognostic association of depression following myocardial infarction with mortality and cardiovascular events: a meta-analysis. Psychosomatic Medicine, 2004. 66(6): p. 814-822.

7. Benton, T., J. Staab, and D.L. Evans, Medical co-morbidity in depressive disorders. Annals of Clinical Psychiatry, 2007. 19(4): p. 289-303.

8. Dickens, C., A. Cherrington, and L. McGowan, Depression and health-related quality of life in people with coronary heart disease: a systematic review. European Journal of Cardiovascular Nursing, 2012. 11(3): p. 265-275.

9. Goldney, R.D., et al., Diabetes, depression, and quality of life a population study. Diabetes Care, 2004. 27(5): p. 1066-1070.

10. Moussavi, S., et al., Depression, chronic diseases, and decrements in health: results from the World Health Surveys. The Lancet, 2007. 370(9590): p. 851-858.

11. Dickens, C., et al., Does depression predict the use of urgent and unscheduled care by people with long term conditions? A systematic review with meta-analysis. Journal of Psychosomatic Research, 2012. 73(5): p. 334-342.

12. Haddad, M., C. Taylor, and S. Pilling, Depression in adults with long term conditions 1: how to identify and assess symptoms. Nursing Times, 2008. 105(48): p. 14-17.

13. Doyle, F., et al., Depressive vulnerabilities predict depression status and trajectories of depression over 1 year in persons with acute coronary syndrome. General Hospital Psychiatry, 2011. 33(3): p. 224-231. 
14. Dickens, C., et al., The risk factors for depression in first myocardial infarction patients. Psychological Medicine, 2004. 34(06): p. 1083-1092.

15. Dickens, C., et al., Depression in rheumatoid arthritis: a systematic review of the literature with meta-analysis. Psychosomatic Medicine, 2002. 64(1): p. 52-60.

16. Rosemann, T., et al., Predictors of depression in a sample of 1,021 primary care patients with osteoarthritis. Arthritis Care \& Research, 2007. 57(3): p. 415-422.

17. Harrison, J. and P. Maguire, Predictors of psychiatric morbidity in cancer patients. British Journal of Psychiatry, 1994. 165(5): p. 593-8.

18. Carney, R.M., et al., Depression as a risk factor for cardiac mortality and morbidity: A review of potential mechanisms. Journal of Psychosomatic Research, 2002. 53(4): p. 897-902.

19. Segerstrom, S.C., et al., A multidimensional structure for repetitive thought: what's on your mind, and how, and how much? Journal of Personality and Social Psychology, 2003. 85(5): p. 909-21.

20. Watkins, E.R., Constructive and unconstructive repetitive thought. Psychological Bulletin, 2008. 134(2): p. 163-206.

21. Nolen-Hoeksema, S., B.E. Wisco, and S. Lyubomirsky, Rethinking Rumination. Perspectives on Psychological Science, 2008. 3(5): p. 400-424.

22. Aldao, A., S. Nolen-Hoeksema, and S. Schweizer, Emotion-regulation strategies across psychopathology: A meta-analytic review. Clinical Psychology Review, 2010. 30(2): p. 217-37.

23. Thomsen, D.K., The association between rumination and negative affect: $A$ review. Cognition \& Emotion, 2006. 20(8): p. 1216-1235.

24. Mor, N. and J. Winquist, Self-focused attention and negative affect: a meta-analysis. Psychological Bulletin, 2002. 128(4): p. 638-62.

25. Teismann, T., et al., Rumination and distraction: selected findings related to the response styles theory. Psychotherapie Psychosomatik Medizinische Psychologie, 2011. 61(3-4): p. 126-32.

26. Morrow, J. and S. Nolen-Hoeksema, Effects of responses to depression on the remediation of depressive affect. Journal of Personality and Social Psychology, 1990. 58(3): p. 519-27.

27. Nolen-Hoeksema, S. and J. Morrow, A prospective study of depression and posttraumatic stress symptoms after a natural disaster: the 1989 Loma Prieta Earthquake. Journal of Personality and Social Psychology, 1991. 61(1): p. 115-21.

28. Nolen-Hoeksema, S. and J. Morrow, Effects of rumination and distraction on naturally occurring depressed mood. Cognition \& Emotion, 1993. 7(6): p. 561-570.

29. Nolen-Hoeksema, S., J. Morrow, and B.L. Fredrickson, Response styles and the duration of episodes of depressed mood. Journal of Abnormal Psychology, 1993. 102(1): p. 20-8.

30. Just, N. and L.B. Alloy, The response styles theory of depression: tests and an extension of the theory. Journal of Abnormal Psychology, 1997. 106(2): p. 221-9. 
31. Nolen-Hoeksema, S., The role of rumination in depressive disorders and mixed anxiety/depressive symptoms. Journal of Abnormal psychology, 2000. 109(3): p. 50411.

32. Spasojevic, J. and L.B. Alloy, Rumination as a common mechanism relating depressive risk factors to depression. Emotion, 2001. 1(1): p. 25-37.

33. Segerstrom, S.C., et al., Worry and rumination: Repetitive thought as a concomitant and predictor of negative mood. Cognitive Therapy and Research, 2000. 24(6): p. 671-688.

34. Lyubomirsky, S. and C. Tkach, The consequences of dysphoric rumination, in Depressive Rumination. 2008, John Wiley \& Sons Ltd. p. 21-41.

35. McLaughlin, K.A., T.D. Borkovec, and N.J. Sibrava, The effects of worry and rumination on affect states and cognitive activity. Behavior Therapy, 2007. 38(1): p. 23-38.

36. Borkovec, T.D., et al., Preliminary exploration of worry: Some characteristics and processes. Behaviour Research and Therapy, 1983. 21(1): p. 9-16.

37. Ciesla, J.A. and J.E. Roberts, Rumination, negative cognition, and their interactive effects on depressed mood. Emotion, 2007. 7(3): p. 555-65.

38. Calmes, C.A. and J.E. Roberts, Repetitive thought and emotional distress: Rumination and worry as prospective predictors of depressive and anxious symptomatology. Cognitive Therapy and Research, 2007. 31(3): p. 343-356.

39. Conway, M., et al., On assessing individual differences in rumination on sadness. Journal of Personality Assessment, 2000. 75(3): p. 404-425.

40. Garnefski, N., et al., Cognitive coping strategies and symptoms of depression and anxiety: a comparison between adolescents and adults. Journal of Adolescence, 2002. 25(6): p. 603-11.

41. Broadbent, E., et al., Psychological stress impairs early wound repair following surgery. Psychosomatic Medicine, 2003. 65(5): p. 865-9.

42. Kubzansky, L.D., et al., Is worrying bad for your heart? A prospective study of worry and coronary heart disease in the Normative Aging Study. Circulation, 1997. 95(4): p. 818-24.

43. Segerstrom, S.C., et al., Relationship of worry to immune sequelae of the Northridge earthquake. Journal of Behavioral Medicine, 1998. 21(5): p. 433-50.

44. CentreforReviewsandDissemination, Systematic reviews: CRD's guidance for undertaking systematic reviews in health care. 2009, CRD, University of York.

45. Moher, D., et al., Preferred reporting items for systematic reviews and metaanalyses: the PRISMA statement. PLoS Med, 2009. 6(7): p. e1000097.

46. Trick, L., E. Watkins, and C. Dickens, The association between perseverative negative cognitive processes and negative affect in people with long term conditions: a protocol for systematic review and meta-analysis. Systematic Reviews, 2014. 3: p. 55. 
47. Flink, I.L., K. Boersma, and S.J. Linton, Pain catastrophizing as repetitive negative thinking: a development of the conceptualization. Cognitive behaviour therapy, 2013. 42(3): p. 215-223.

48. Sullivan, M.J., et al., Theoretical perspectives on the relation between catastrophizing and pain. Clinical Journal of Pain, 2001. 17(1): p. 52-64.

49. Thomas, B.H., et al., A process for systematically reviewing the literature: providing the research evidence for public health nursing interventions. Worldviews Evidence Based Nursing, 2004. 1(3): p. 176-84.

50. Popay, J., et al., Guidance on the conduct of narrative synthesis in systematic reviews: A product from the ESRC methods programme. 2006, Institute for Health Research, University of Lancaster

51. Andreu, Y., et al., A longitudinal study of psychosocial distress in breast cancer: prevalence and risk factors. Psychology and Health, 2012. 27(1): p. 72-87.

52. Baker, L., A prospective longitudinal study of repetitive thought as a vulnerability factor for depression in patients with coronary heart disease. 2014, University of Exeter: University of Exeter ORE.

53. Couper, J.W., et al., Predictors of psychosocial distress 12 months after diagnosis with early and advanced prostate cancer. Medical Journal of Australia, 2010. 193(5): p. S58.

54. Denton, E.D., et al., Rumination as a depression vulnerability after acute coronary syndrome. Psychosomatic Medicine, 2011. 73 (3): p. A77.

55. Denton, E.G., et al., Psychosocial vulnerabilities to depression after acute coronary syndrome: the pivotal role of rumination in predicting and maintaining depression. Frontiers in Psychology, 2012. 3: p. 288.

56. Ferrero, J., M.P. Barreto, and M. Toledo, Mental adjustment to cancer and quality of life in breast cancer patients: An exploratory study. Psycho-Oncology, 1994. 3(3): p. 223-232.

57. Garnefski, N. and V. Kraaji, Do cognitive coping and goal adjustment strategies used shortly after myocardial infarction predict depressive outcomes 1 year later? Journal of Cardiovascular Nursing, 2010. 25(5): p. 383-9.

58. Groarke, A., R. Curtis, and M. Kerin, Global stress predicts both positive and negative emotional adjustment at diagnosis and post-surgery in women with breast cancer. Psycho-Oncology, 2013. 22(1): p. 177-85.

59. Hanley, M.A., et al., Psychosocial predictors of long-term adjustment to lower-limb amputation and phantom limb pain. Disability and Rehabilitation, 2004. 26(14-15): p. 882-93.

60. Jensen, M.P., et al., Cognitions, coping and social environment predict adjustment to phantom limb pain. Pain, 2002. 95(1-2): p. 133-42.

61. Jensen, M.P., J.M. Engel, and L. Schwartz, Coping with cerebral palsy pain: $a$ preliminary longitudinal study. Pain Medicine, 2006. 7(1): p. 30-7. 
62. Jensen, M.P., J.A. Turner, and J.M. Romano, Changes in beliefs, catastrophizing, and coping are associated with improvement in multidisciplinary pain treatment. Journal of Consulting and Clinical Psychology, 2001. 69(4): p. 655-62.

63. Keefe, F.J., et al., Coping with rheumatoid arthritis pain: catastrophizing as a maladaptive strategy. Pain, 1989. 37(1): p. 51-6.

64. Kraaij, V., et al., Cognitive coping, goal adjustment, and depressive and anxiety symptoms in people undergoing infertility treatment: a prospective study. Journal of Health Psychology, 2010. 15(6): p. 876-86.

65. Kraaij, V., N. Garnefski, and A. Vlietstra, Cognitive coping and depressive symptoms in definitive infertility: a prospective study. Journal of Psychosomatic Obstetrics \& Gynecology, 2008. 29(1): p. 9-16.

66. Lampic, C., et al., Coping, psychosocial well-being and anxiety in cancer patients at follow-up visits. Acta Oncologica, 1994. 33(8): p. 887-894.

67. Lehto, R.H. and B. Cimprich, Worry and the formation of cognitive representations of illness in individuals undergoing surgery for suspected lung cancer. Cancer Nursing, 2009. 32(1): p. 2-10.

68. Nieto, R., et al., Changes in pain-related beliefs, coping, and catastrophizing predict changes in pain intensity, pain interference, and psychological functioning in individuals with myotonic muscular dystrophy and facioscapulohumeral dystrophy. Clinical Journal of Pain, 2012. 28(1): p. 47-54.

69. Schiaffino, K.M. and T.A. Revenson, Why me? The persistence of negative appraisals over the course of illness. Journal of Applied Social Psychology, 1995. 25(7): p. 601618.

70. Sharpe, L., T. Sensky, and S. Allard, The course of depression in recent onset rheumatoid arthritis: the predictive role of disability, illness perceptions, pain and coping. Journal of Psychosomatic Research, 2001. 51(6): p. 713-9.

71. Sturgeon, J.A. and A.J. Zautra, State and trait pain catastrophizing and emotional health in rheumatoid arthritis. Annals of Behavioral Medicine, 2013. 45(1): p. 69-77.

72. Turner, J.A., L. Mancl, and L.A. Aaron, Pain-related catastrophizing: a daily process study. Pain, 2004. 110(1-2): p. 103-11.

73. Vögele, C., O. Christ, and H. Spaderna, Cardiac threat appraisal and depression after first myocardial infarction. Frontiers in Psychology, 2012. 3: p. 365.

74. Vollmer, T.C., et al., Preoccupation with death as predictor of psychological distress in patients with haematologic malignancies. European Journal of Cancer Care, 2011. 20(3): p. 403-411.

75. Wang, Y., et al., Cognitive emotion regulation strategies as predictors of depressive symptoms in women newly diagnosed with breast cancer. Psycho-Oncology, 2014. 23(1): p. 93-99.

76. Xiao, J., et al., A prospective study of cognitive emotion regulation strategies and depressive symptoms in patients with essential hypertension. Clinical \& Experimental Hypertension, 2011. 33(1): p. 63-8. 
77. Bourgault, P., et al., Multicomponent interdisciplinary group intervention for selfmanagement of fibromyalgia: a mixed-methods randomized controlled trial. PLoS One, 2015. 10(5): p. e0126324.

78. Lam, W.W., et al., The evolution of psychological distress trajectories in women diagnosed with advanced breast cancer: a longitudinal study. Psycho-Oncology, 2013. 22(12): p. 2831-9.

79. Mehlsen, M., L. Heegaard, and L. Frostholm, A prospective evaluation of the Chronic Pain Self-Management Programme in a Danish population of chronic pain patients. Patient Education and Counseling, 2015. 98(5): p. 677-80.

80. Sparkes, E., et al., Analysis of psychological characteristics impacting spinal cord stimulation treatment outcomes: a prospective assessment. Pain Physician, 2015. 18(3): p. E369-77.

81. Thomsen, D., et al., Rumination, reflection and distress: An 8-month prospective study of colon-cancer patients. Cognitive Therapy and Research, 2013. 37(6): p. 1262-1268.

82. Rzewuska, M., et al., One-year trajectories of depression and anxiety symptoms in older patients presenting in general practice with musculoskeletal pain: A latent class growth analysis. J Psychosom Res, 2015. 79(3): p. 195-201.

83. Carver, C.S. and M.F. Scheier, Origins and functions of positive and negative affect: $A$ control-process view. Psychological Review, 1990. 97(1): p. 19-35.

84. Martin, L.L. and A. Tesser, Some ruminative thoughts, in Ruminative thoughts. 1996, Lawrence Erlbaum Associates, Inc: Hillsdale, NJ, US. p. 1-47. 


\section{Supplementary material}

\section{Appendix A: Search strategy}

The same search strategy was used with alterations as appropriate for each database.

1 depression.ti,ab,sh.

2 depressive disorder.ti,ab,sh.

3 anxiety.ti,ab,sh.

4 anxiety disorder*.ti,ab. or anxiety disorders.sh.

5 stress, psychological.sh.

6 psychological distress.ti,ab.

7 emotional distress.ti,ab.

$8 \quad 1$ or 2 or 3 or 4 or 5 or 6 or 7

9 perseverative.ti,ab. and cognition.ti,ab,sh.

10 (perseverative and cognitive and processes).ti,ab.

11 perseverative.ti,ab. and thinking.ti,ab,sh.

12 (perseverative and thought).ti,ab.

13 repetitive.ti,ab. and thinking.ti,ab,sh.

14 (repetitive and thought).ti,ab.

15 (worry* or worrie* or worrisome).ti,ab.

16 ruminat*.ti,ab.

17 response styles theory.ti,ab.

18 brooding.ti,ab.

19 preoccupation.ti,ab.

20 (self focus or self focused attention).ti,ab.

21 emotion regulation.ti,ab.

22 coping strateg*.ti,ab.

23 coping style.ti,ab.

249 or 10 or 11 or 12 or 13 or 14 or 15 or 16 or 17 or 18 or 19 or 20 or 21 or 22 or 23

25 longitudinal studies.sh. or longitudinal study.ti,ab.

26 prospective studies.sh. or prospective study.ti,ab.

27 followup studies.sh. or follow up.ti,ab.

28 baseline.ti,ab.

29 experience sampling.ti,ab.

30 time series.ti,ab.

31 induction*.ti,ab.

3225 or 26 or 27 or 28 or 29 or 30 or 31

$33 \quad 8$ and 24 and 32 


\section{Appendix B: Additional methodological details}

\section{Study selection}

Eligibility screening took place in two stages. First, titles and abstracts were independently screened by two reviewers (LT, SH) to identify potentially relevant studies. Studies that did not meet specific inclusion/exclusion criteria at this stage were rejected, and disagreements between the two reviewers were resolved by discussion, with the involvement of a third reviewer (CD) where agreement could not be reached. Next, full text copies of all remaining records were obtained and independently assessed by two reviewers (LT, SW). Again, studies that did not meet specific inclusion/exclusion criteria were rejected, and the reason for rejection was recorded. Multiple reports of the same study were combined and counted only once.

\section{Data extraction}

Data from all included studies was extracted independently by two reviewers (LT, SW) into a standardised data extraction form that was piloted on three studies, with adaptations made in a stepwise fashion. Discrepancies were resolved by discussion. Data extracted included details of study design, sample characteristics and demographics, measures of perseverative negative thinking and psychological outcomes (i.e. depression, anxiety or emotional distress), frequency and timing of assessments, measures of physical health/medical outcomes, statistical methods including variables controlled for, outcomes of statistical analyses, and information relating to quality assessment. Authors of included studies were contacted to provide missing or additional data where necessary.

\section{Quality assessment/risk of bias}

The Effective Public Health Practice Project (EPHPP) Quality Assessment Tool[49] was used to assess risk of bias within each study. Ratings were made for six components: selection bias, study design, confounders, blinding, data collection methods, and withdrawals. Each component was rated strong, moderate or weak. Component ratings were combined into a global score of strong where there were at least 4 strong and no weak component ratings, moderate where there was 1 weak component rating, and weak where 
there were two or more weak component ratings. Quality was independently evaluated by two reviewers (LT, SW) at outcome level.

We modified two of the risk of bias components in light of the design of the included studies. First, the confounders component is intended to evaluate whether there were important differences between study groups prior to an intervention. However, as there were no group comparisons in the included studies (or data related to group comparisons was not extracted because it was not relevant) we evaluated 'Were any relevant confounders controlled for, in the design of the study or in the analysis?'. Relevant confounders were defined as age, sex and baseline depression as these are all known to be associated with depression. Studies were rated strong where all three of these confounders were controlled for, moderate where some of these confounders were controlled for, and weak where no confounders (or others not listed) were controlled for. Second, the blinding component is intended to evaluate whether outcome assessors were aware of the intervention or exposure status of participants. However, as participants were not allocated to groups or conditions in the included studies (or if they were, data relating to groups or conditions was not extracted because it was not relevant) the blinding component evaluated: (a) 'was the researcher exposed to information about the participant that could lead to bias?' For example, was the researcher aware of participants' previous responses when administering questionnaires, or did researchers have access to participant data from previous or other assessments when scoring questionnaires, and (b) 'was the participant aware of the research question?'. 
Appendix C: Vote count of studies that report an association between perseverative negative thinking and psychological outcomes

(multivariable findings)

\begin{tabular}{|c|c|c|c|c|c|c|c|}
\hline & & Depression & Anxiety & $\begin{array}{c}\text { Negative } \\
\text { affect }\end{array}$ & Distress & $\begin{array}{l}\text { Psychological } \\
\text { functioning }\end{array}$ & $\begin{array}{c}\text { Negative } \\
\text { mood }\end{array}$ \\
\hline \multirow[t]{3}{*}{ Heart disease } & Rumination & 1345 & & & & & \\
\hline & Catastrophizing & 5 & & & & & \\
\hline & Rumination/catastrophizing & 2 & & & & & \\
\hline \multirow[t]{2}{*}{ RA } & Rumination & $8^{R}$ & & & & & \\
\hline & Catastrophizing & 679 & 9 & 7 & & & \\
\hline \multirow[t]{4}{*}{ Cancer } & Anxious preoccupation & 1316 & 1316 & 13 & 12 & & \\
\hline & Preoccupation with death & $1919^{R}$ & $1919^{R}$ & & & & \\
\hline & Catastrophizing & 10 & & & & & \\
\hline & Rumination & 101415 & 14 & & & & \\
\hline \multirow[t]{3}{*}{ Infertility } & Catastrophizing & 20 & & & & & \\
\hline & Rumination & 20 & & & & & \\
\hline & Rumination/catastrophizing & 21 & 21 & & & & \\
\hline $\begin{array}{c}\text { Muscular } \\
\text { dystrophy/Cerebral } \\
\text { palsy }\end{array}$ & Catastrophizing & & & & & $22^{\mathrm{C}}$ & \\
\hline \multirow[t]{2}{*}{$\begin{array}{l}\text { Pain-related } \\
\text { conditions }\end{array}$} & Catastrophizing & $\begin{array}{c}25^{\mathrm{CE}} 26^{\mathrm{C}} 27 \\
282930\end{array}$ & $\begin{array}{c}2728 \\
30\end{array}$ & & & & \\
\hline & Rumination/catastrophizing & & & & & & 24 \\
\hline
\end{tabular}

Red=No association Green=Association Black=Mixed evidence

Numbers refer to study ID (see Tables 1 to 3 )

Empty cells represent no relevant results

${ }_{R}^{R}=$ reverse relationship (i.e. T1 negative affect associated with $T 2$ perseverative negative thinking)

${ }^{c}=$ change scores (i.e. change in perseverative negative thinking associated with change in negative affect)

${ }^{E}=$ association not in expected direction 